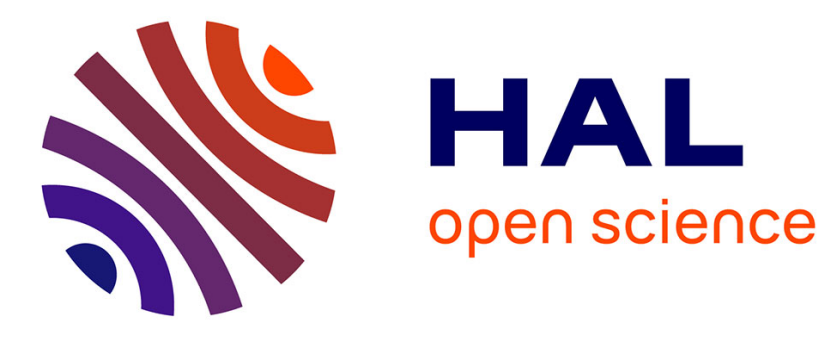

\title{
Golgi trafficking defects in postnatal microcephaly: The evidence for "Golgipathies"
}

Sandrine Passemard, Franck Perez, Emilie Colin-Lemesre, Sowmyalakshmi Rasika, Pierre Gressens, Vincent El Ghouzzi

\section{- To cite this version:}

Sandrine Passemard, Franck Perez, Emilie Colin-Lemesre, Sowmyalakshmi Rasika, Pierre Gressens, et al.. Golgi trafficking defects in postnatal microcephaly: The evidence for "Golgipathies". Progress in Neurobiology, 2017, 153 (3), pp.46-63. 10.1016/j.pneurobio.2017.03.007 . hal-02322811

\section{HAL Id: hal-02322811 \\ https://hal.science/hal-02322811}

Submitted on 2 Jun 2020

HAL is a multi-disciplinary open access archive for the deposit and dissemination of scientific research documents, whether they are published or not. The documents may come from teaching and research institutions in France or abroad, or from public or private research centers.
L'archive ouverte pluridisciplinaire HAL, est destinée au dépôt et à la diffusion de documents scientifiques de niveau recherche, publiés ou non, émanant des établissements d'enseignement et de recherche français ou étrangers, des laboratoires publics ou privés. 


\section{Golgi trafficking defects in postnatal microcephaly: the evidence for "Golgipathies"}

Sandrine Passemard ${ }^{1,2}$, Franck Perez ${ }^{3}$, Emilie Colin-Lemesre ${ }^{1,3}$, Sowmyalakshmi Rasika $^{1}$, Pierre Gressens ${ }^{1,4}$, Vincent El Ghouzzi ${ }^{1 *}$ (1)

2. AP HP, Hôpital Robert Debré, Service de Génétique Clinique, Paris, France

3. Institut Curie, PSL Research University, CNRS, UMR144, Paris, France

4. Centre for the Developing Brain, Division of Imaging Sciences and Biomedical Engineering, King's College London, King's Health Partners, St. Thomas' Hospital, London, United Kingdom

\section{*Corresponding author:}

\section{Vincent El Ghouzzi}

Address: Inserm U1141, Hôpital Robert-Debré, 48 Boulevard Sérurier, F-75019, Paris, France.

E-mail: vincent.elghouzzi@inserm.fr

Phone: +331 40031973, Fax: +331 40031995

Key words: Golgi apparatus; RAB GTPase; neuronal trafficking; postnatal microcephaly; intellectual disability; Golgipathies

Number of words in the abstract: 225

Number of words in the body of the manuscript: 9,641 
Abstract

3 The Golgi apparatus plays a central role in cell homeostasis, not only in processing and

4 maturing newly synthesized proteins and lipids but also in orchestrating their sorting, packing,

5 routing and recycling on the way to their final destination. These multiple secretory pathways

6 require a complex ballet of vesicular and tubular carriers that continuously bud off from donor

7 membranes and fuse to acceptor membranes. Membrane trafficking is particularly prominent in

8 axons, where cargo molecules have a long way to travel before they reach the synapse, and in

9 oligodendrocytes, which require an immense increase in membrane surface in order to sheathe

10 axons in myelin. Interestingly, in recent years, genes encoding Golgi-associated proteins with a

11 role in membrane trafficking have been found to be defective in an increasing number of

12 inherited disorders whose clinical manifestations include postnatal-onset microcephaly (POM),

13 white matter defects and intellectual disability. Several of these genes encode RAB GTPases,

14 RAB-effectors or RAB-regulating proteins, linking POM and intellectual disability to RAB-

15 dependent Golgi trafficking pathways and suggesting that their regulation is critical to postnatal

16 brain maturation and function. Here, we review the key roles of the Golgi apparatus in post-

17 mitotic neurons and the oligodendrocytes that myelinate them, and provide an overview of

18 these Golgi-associated POM-causing genes, their function in Golgi organization and trafficking

19 and the likely mechanisms that may link dysfunctions in RAB-dependent regulatory pathways

20 with POM. 


\section{Contents}

2 1. Introduction 4

3

7. References
6

2.1 Role of the Golgi apparatus in neuronal polarity...... 6

2.1.1 Distribution of microtubules in neurons and their relationship to the Golgi

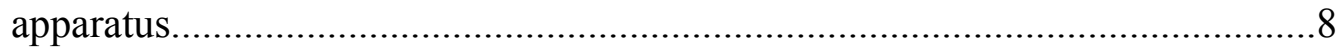

2.1.2 Specificity of Golgi-derived transport carriers..............................................

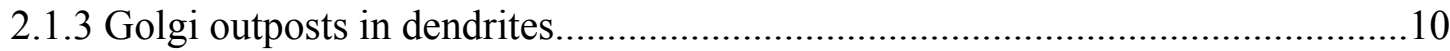

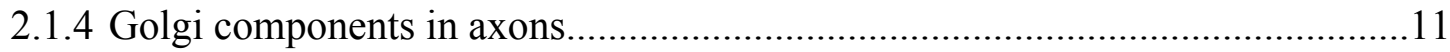

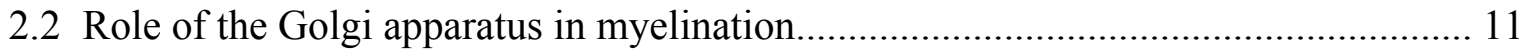

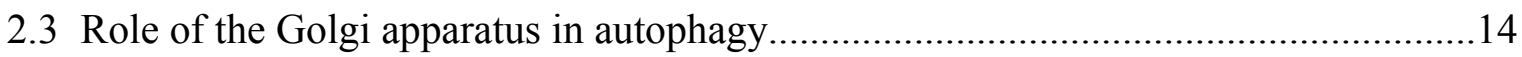

2.4 Role of Golgi-associated RAB proteins in the brain............................................... 16

3. Syndromes with postnatal onset microcephaly (POM) and causative genes.................... 20

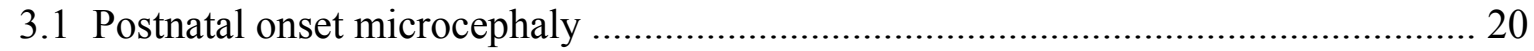

3.2 Golgi-associated proteins implicated in POM........................................................ 22

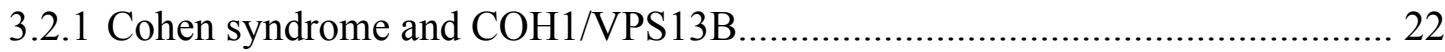

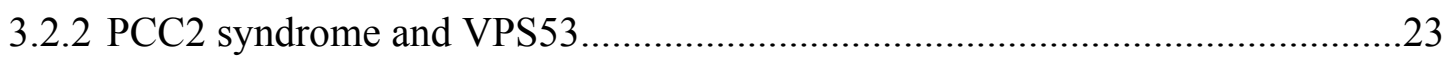

3.2.3 Warburg-Micro syndrome and RAB3GAP1/2, RAB18 and TBC1D20_.......... 24

3.2.4 Autosomal recessive mental retardation 13 (MRT13) and TRAPPC9..............25

3.2.5 A neuromuscular syndrome with microcephaly and GOLGA2/GM130...........26

3.2.6 Dyggve-Melchior-Clausen syndrome and DYMECLIN_............................... 27

3.2.7 Congenital disorders of glycosylation and COG complex..............................28

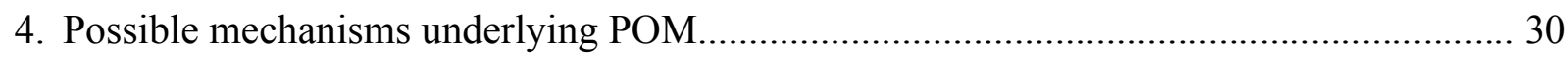

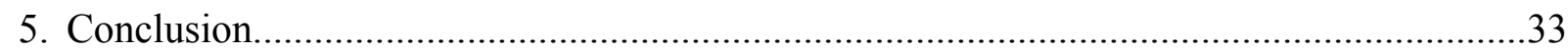

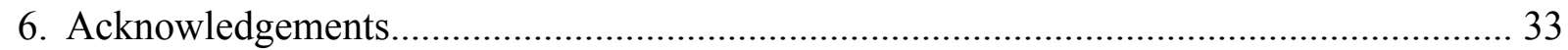




\section{Introduction}

Microcephaly affects about $2 \%$ of the population worldwide and represents the most frequent neurological sign encountered in developmental brain disorders. It is characterized by a small brain size, indirectly diagnosed by an occipito-frontal or head circumference (OFC) smaller than the age- and gender-adjusted mean by more than 2 standard deviations (SD) at birth and/or $3 \mathrm{SD}$ as measured at 6 months of age or later; it is frequently associated with intellectual disability of variable severity. Among the many kinds of microcephaly, genetic forms have yielded essential information as to how the human brain develops during embryonic/fetal and postnatal periods. While primary microcephaly is defined by a congenital failure of brain growth detectable before birth, secondary (or postnatal-onset) microcephaly $(\mathrm{POM})$ is characterized by normal brain size at birth and the subsequent deceleration of brain growth, and in particular the white matter, during infancy and/or childhood. In the past 15 years, considerable efforts have led to the identification of genes and pathways whose deficiency causes hereditary primary microcephaly, also known as MCPH. The vast majority of MCPH genes (17 identified to date, see updated review by (Alcantara and O'Driscoll, 2014)) play a role in the regulation of cell division and/or centrosome function in neural progenitors, and a large number of functional studies now converge on common mechanisms that affect the mode and/or extent of cortical progenitor division and their subsequent survival and differentiation during the development of the neocortex. In contrast, POM or acquired microcephaly, which often appears to be only one of many clinical signs in complex and divergent syndromes, is not always considered a disorder on its own. As such, it is underdiagnosed and underinvestigated, and the cellular mechanisms leading to it are poorly understood.

The timing of POM suggests that these cellular mechanisms presumably involve processes and pathways that occur later during development than neuronal progenitor division, the major process implicated in primary microcephaly. Indeed, several principally postnatal 
1 mechanisms that could lead to POM, such as defective gliogenesis or myelination, the

2 impairment of neuronal maturation or synaptic pruning, the arrest of normal development or

3 degenerative processes, have received much attention from the scientific community in recent

4 years. One candidate process worth noting is membrane trafficking and secretion through the

5 Golgi apparatus. Indeed, several recent studies have implicated Golgi-associated proteins in

6 genetic disorders that include POM among their characteristics, suggesting that the regulation

7 of Golgi trafficking and secretory functions are critical to postnatal brain maturation.

8 Intriguingly, a number of these POM-causing genes encode either RAB proteins - members of

9 the RAS superfamily of small GTPases which play a central role in membrane trafficking

10 including Golgi organization, vesicle formation, transport and fusion - or RAB-associated or

11 RAB-tethering factors whose fast and reversible recruitment facilitates such trafficking.

12 Interestingly, all these POM-causing genes are associated with the defective development of

13 white matter, which consists principally of the axons of neurons and the myelinating

14 oligodendrocytes that ensheathe them, highlighting the link between the heavy membrane

15 trafficking and secretory activity of these two interdependent cellular components and postnatal

16 brain development.

17 In this review, we describe the key roles played by the Golgi apparatus in post-mitotic 18 neurons and oligodendrocytes, describe recently identified POM-causing genes associated with 19 the Golgi apparatus, and discuss the intriguing fact that many of these appear to encode RAB 20 proteins or their molecular partners. In light of their role in Golgi organization and trafficking 21 and the mechanistic links between RAB proteins, white matter defects and the development of 22 POM, we propose a new term for these disorders based on their similar pathophysiology:

23 "Golgipathies"/"Golgipathic microcephalies". 


\section{The Golgi apparatus in post-mitotic neurons and oligodendrocytes}

The Golgi apparatus is a multifunctional organelle essential to ensure differentiated cellular functions as well as to maintain cell homeostasis. In mammalian cells, about one-third of newly synthesized proteins are destined to be secreted following the conventional secretory pathway. The Golgi apparatus is primarily involved in the processing of secretory proteins and lipids as they transit through it, effecting posttranslational modifications such as glycosylation, sulfation and proteolytic cleavage. The Golgi apparatus also acts in the sorting, packing, routing and recycling of these cargo molecules for their final destination. Depending on the cell type and stage of development, Golgi-dependent trafficking routes and secretory cargos have become diversified to fulfill specific secretory functions (Boncompain and Perez, 2013a). This is especially true of two cell types that are heavily affected in POM: post-mitotic projection neurons and the oligodendrocytes that enwrap their axons in myelin, with several studies showing that the Golgi apparatus plays a key role in the dynamic trafficking specific to the axonal and dendritic compartments of these neurons, as well as the extensive plasma membrane extensions of oligodendrocytes required for myelin formation. Besides its involvement in protein and lipid trafficking/processing in these two cell types, the Golgi apparatus is also involved in the determination and maintenance of neuronal polarity, as well as in autophagy, another process essential both for brain development and homeostasis of mature neural cells.

\subsection{Role of the Golgi apparatus in neuronal polarity}

In mammalian cells, the Golgi apparatus is a ribbon-shaped organelle made up of flattened cisternae organized into polarized stacks, flanked on either side by fenestrated tubular reticular membranes called the cis-Golgi network (CGN) and the trans-Golgi network (TGN) (Nakamura et al., 2012; Papanikou and Glick, 2014). In most cells, the Golgi apparatus is positioned near or around the centrosome, with which it is dynamically associated through the action of cytoplasmic dynein motor proteins and Golgi anchor proteins (Yadav and Linstedt, 2011). In developing neurons, centrosomes, the Golgi apparatus and endosomes cluster 
1 together at one pole of the cell body before neurites form, and play a key role in axon

2 specification (Caceres, 2007). Although the existence of a direct correlation between

3 Golgi/centrosome positioning and the area where the future axon will form has remained

4 controversial (de Anda et al., 2005; Distel et al., 2010; Horton et al., 2005; Lowenstein et al.,

5 1994; Zmuda and Rivas, 1998), this asymmetric pericentrosomal confinement of the Golgi

6 apparatus likely leads to a local concentration of neuronal growth potential both in terms of

7 cytoskeletal infrastructure and of newly synthesized proteins, two components essential for the

8 elongation of the axon. Axonal outgrowth also requires a huge expansion of the plasma

9 membrane surface (Horton and Ehlers, 2003), which is achieved by the progressive integration

of Golgi-derived vesicles. Such vesicles have been shown to accumulate and polarize before

11 axonogenesis in cultured hippocampal neurons (Bradke and Dotti, 1997). In line with this

12 mechanism, brefeldin A treatment, which disassembles the Golgi apparatus, results in the

13 selective inhibition of axonal growth (Jareb and Banker, 1997). Similarly, the genetic

14 invalidation of certain Golgi-related proteins leads to altered neuronal polarity and death and/or

15 dysfunction. For instance, in mice in which the expression of the golgin GM130 is invalidated

16 by shRNA treatment or genetically knocked out, the polarity of the Golgi apparatus is altered,

17 leading to altered dendritic polarization in granule cells of the hippocampus (Huang et al.,

18 2014), as well as altered ER-to-Golgi transport, inducing the atrophy and death of Purkinje

19 cells of the cerebellum, and consequently, ataxia (Liu et al., 2017). The loss of expression of

20 two other golgins, Golgin-160 and GMAP210, which disrupt pericentrosomal Golgi positioning

21 without affecting either the microtubule network or general secretion, also strongly affects cell

22 polarity in vitro (Yadav et al., 2009). However, the effect of GMAP120 deletion on Golgi

23 structure or function might depend on the cellular subtype being examined (Smits et al., 2010).

In addition to its involvement in neuronal development, the Golgi apparatus is required

26 for the maintenance of axodendritic polarity throughout the lifespan of mature post-mitotic 
1 neurons. These highly specialized cells possess specific architectural features that make the

2 secretory pathway central to their structural maintenance, dynamics and function. In particular, 3 their strongly polarized axons and dendrites are characterized by morphologically and

4 functionally distinct components and pathways. This necessitates the asymmetric transport of

5 membranes and the continuous targeting of distinct repertoires of cargo proteins and lipids to

6 these distinct subcellular compartments. Mature neurons also often develop extensive dendritic

7 branching accompanied by a huge increase in membrane surface area (Ye et al., 2006). In

8 addition, the long axons possessed by some neurons pose a perennial challenge to the

9 movement of proteins, lipids, vesicles and organelles between cell bodies and synaptic sites.

10 Although the mechanisms through which this differential targeting is specifically achieved and

11 regulated are complex and only partially understood, a number of key findings show that the

12 Golgi apparatus lies at the core of processes that elicit distinct secretory features in the axons 13 and dendrites of post-mitotic neurons, thereby maintaining neuronal polarity.

2.1.1 Distribution of microtubules in neurons and their relationship to the Golgi

apparatus

Microtubules, which themselves are polarized and serve as rails for active vesicular cargo transport driven by molecular motors, are asymmetrically distributed in axons and dendrites. While axons usually display long, uniformly oriented microtubules with their minus ends towards the soma and the plus ends facing outwards, proximal dendrites contain shorter microtubules oriented in both directions (Baas, 1999) (Figure 1A). In dendrites, the minus-endout microtubules are generally more stable (Yau et al., 2016), which contributes to generating directionality. This implies a difference in the organization of molecular motors involved in trafficking in the two compartments. For example, dynein, which moves along microtubules towards their minus end, drives retrograde transport in axons but bidirectional transport in dendrites, while kinesin motors seem to predominantly drive anterograde transport in axons 
1 (Kapitein et al., 2010). Interestingly, the Golgi apparatus not only sorts and provides the

2 various cargos to be conveyed to specific destinations but also acts as a microtubule-organizing

3 center (MTOC), independently of the centrosome (Chabin-Brion et al., 2001; Zhu and

4 Kaverina, 2013), and itself generates a distinct population of microtubules called Golgi-derived

5 microtubules. During the development of rodent hippocampal neurons, the centrosome actually

6 loses its function as an MTOC, and it is microtubules of non-centrosomal origin that enable

7 axon extension and serve as rails for directional post-Golgi trafficking (Stiess et al., 2010).

8 Similarly, microtubule organization is independent of the centrosome in developing and mature

9 Drosophila neurons (Nguyen et al., 2011), and the Golgi apparatus has been proposed as a possible source of dendritic microtubules (Ori-McKenney et al., 2012), a process promoted by

11 the golgin GM130 (Zhou et al., 2014). Interestingly, directional trafficking defects have been 12 observed in human RPE1 cells lacking Golgi-derived microtubules, suggesting that the latter 13 are essential for post-Golgi transport (Miller et al., 2009; Vinogradova et al., 2012). Thus, 14 while further evidence is still required to confirm this possibility, the Golgi apparatus might 15 also be directly involved in the maintenance of neuronal polarity in postmitotic neurons 16 through its role as an MTOC.

17

\subsubsection{Specificity of Golgi-derived carriers}

The differential distribution of cargo proteins and lipids between dendrites and axons is largely due to specific and reciprocal interactions between cargos, their carriers and molecular motors. This occurs through the docking of motor proteins onto their specific cargos either directly or via adaptor molecules, including scaffolding proteins, receptors and Rab GTPases that regulate neuronal transport (Franker and Hoogenraad, 2013; Maeder et al., 2014; Schlager and Hoogenraad, 2009). Interestingly, the identity of the various carriers is in large part conferred by the specific cargos they carry. The sorting of axonal and dendritic cargo proteins and lipids occurs in the TGN, where they are physically segregated into specific clusters that 
1 define specific dynamic TGN subdomains, ultimately leading to vesicle budding. This physical

2 segregation of cargos appears to rely on both the intrinsic affinity of different cargos for

3 specific lipid microenvironments provided by the TGN (Brugger et al., 2000; Klemm et al.,

4 2009; Orci et al., 1987; Paladino et al., 2004; Schuck and Simons, 2004); reviewed in (Anitei

5 and Hoflack, 2011; De Matteis and Luini, 2008; Guo et al., 2014; Lingwood and Simons, 2010;

6 Surma et al., 2012), and the presence of sorting signals on cargo molecules that target them to

7 TGN-specific adaptors such as small ADP ribosylation factors, Rab and Rho GTPases, and

8 Golgi-localized tethering factors (De Matteis and Luini, 2008). In other words, the selective

9 targeting of cargos that contribute to the axodendritic polarity of neurons starts as soon as the cargos reach the TGN (Guo et al., 2014).

\subsubsection{Golgi outposts in dendrites}

In addition to the somatic Golgi apparatus, the Golgi complex forms smaller satellite structures called Golgi outposts that are found in about $20 \%$ of the dendrites of mature neurons (Gardiol et al., 1999; Horton et al., 2005; Pierce et al., 2001) (Figure 1A). Several studies have provided evidence that these Golgi outposts lack continuity with the somatic Golgi apparatus and are functionally independent. Golgi outposts ensure the post-translational modifications, trafficking and sorting of locally synthesized proteins (Horton et al., 2005; Jeyifous et al., 2009; Torre and Steward, 1996; Ye et al., 2007), as well as local microtubule nucleation (OriMcKenney et al., 2012), thereby playing a major role both in shaping dendritic arbor morphology and in serving as platforms for the local delivery of postsynaptic molecules such as synaptic receptors. In line with this role, and consistent with the recent demonstration that Golgi outposts destined for the major dendrite are generated by a sequential process that involves the polarized deployment and fission of tubules derived from the somatic Golgi (Quassollo et al., 2015), markers of cis, medial and trans Golgi compartments have all been 
1 apparatus in the functional specialization of dendrites, a recent study by Mikhaylova provides

2 evidence for a Golgi-related satellite microsecretory system in dendrites that is even more

3 widespread than Golgi outposts and would permit the autonomous local control of membrane

4 protein synthesis and processing within dendrites (Mikhaylova et al., 2016).

5

6

\subsubsection{Golgi components in axons}

Besides the well-described transport mechanisms that direct cargos to axons through molecular motors and microtubules, and ensure their activity, function and plasticity (Hirokawa and Takemura, 2005), growing evidence suggests that a number of axonal proteins are locally synthesized from mRNAs and ribosomes present in axons and presynaptic elements (SoteloSilveira et al., 2006; Yoo et al., 2010). The existence of such decentralized protein synthesis could allow axons to meet local demands in a fast and energy-efficient manner, as is the case with dendrites (Donnelly et al., 2010; Holt and Bullock, 2009; Jung et al., 2012). However, whether this process also involves the presence of Golgi outpost-like structures in axons is a matter of debate. The presence of early secretory components, including markers of the ER, the ER-Golgi intermediate compartment (ERGIC), Golgi apparatus and TGN, has been observed by some authors in the distal axoplasm of rat peripheral axons (Gonzalez et al., 2016; Merianda et al., 2009), raising the possibility that these components self-organize into small functional organelles in situ. Although rough ER and Golgi stacks have not so far been observed in axons at the ultrastructural level (reviewed in (Ramirez and Couve, 2011)), the occurrence of local protein synthesis suggests that protein processing and secretory needs could also be met locally, rendering axons at least partially independent of the somatic early secretory pathway and facilitating, for example, fast membrane receptor recycling in response to local conditions.

\subsection{Role of the Golgi apparatus in myelination}


Most neurons are characterized by a myelin sheath that enwraps their axons and is responsible for the whitish appearance of the white matter of the brain. In the central nervous

3 system (CNS), the myelin sheath is a multilamellar structure consisting of the plasma membrane extensions of oligodendrocytes, with a single mature oligodendrocyte ensheathing several axons. These lipid-rich processes are extremely long and packed in tight spirals around axons, forming a dense sheath to protect and insulate them and thus ensure the high-speed propagation of electrical impulses. A stereological study carried out in a 20 year-old man has revealed a total myelinated fiber length of 170,000 kilometers (Marner et al., 2003); the dimensions of the oligodendrocytic processes required to ensheathe these fibers must therefore be many times greater. The biogenesis and maintenance of this vast quantity of myelin implies an intensive and sustained supply of membrane proteins and lipids. In oligodendrocytes, as in neurons, this is achieved both through the local synthesis of myelin components close to the site of their assembly, and through intensive vesicle trafficking mechanisms involving the traditional ER-Golgi-TGN pathway (Kramer et al., 2001). For example, myelin basic protein (MBP), which represents approximately 30 percent of myelin proteins and plays a major role in myelin compaction (Privat et al., 1979) and composition by regulating its protein to lipid ratio

17 (Aggarwal et al., 2011), is synthesized on the spot by the local translation of MBP mRNAs 18 (Colman et al., 1982), following their packing in a translationally repressed state (Bauer et al., 2012; Kosturko et al., 2006) into large ribonucleoprotein complexes called RNA transport granules (Muller et al., 2013), and their transport along microtubules into the myelin compartment (Ainger et al., 1993; Carson et al., 1997). In contrast, myelin-specific lipids and other major myelin proteins, such as the proteolipid protein PLP, are synthesized in the soma of mature oligodendrocytes and pass through the Golgi where they are processed and self24 assemble with cholesterol and sphingolipids to form a type of preformed myelin modules called lipid-enriched liquid ordered membrane microdomains or lipid "rafts", which are transported 
1 technical complications inherent in observing nanoscale molecular organizations such as lipid

2 microdomains in a reliable manner, i.e. without altering the object of the observation, has no

3 doubt contributed to their being viewed by some authors as hypothetical rather than real

4 structures for the present (see (Guo et al., 2014)). Reciprocal communication between axons

5 and oligodendrocytes is also required for the generation of the myelin sheath. In

6 oligodendrocytes, such lipid microdomains, in addition to being components of myelin, behave

7 as dynamic signaling modules in recruiting specific signaling proteins that integrate axon-

8 derived soluble or membrane-bound signals to regulate myelination spatiotemporally (White

9 and Kramer-Albers, 2014). The nodes of Ranvier, non-myelinated axon segments that are

10 regularly placed along myelinated fibers, constitute privileged zones where molecular

11 interchanges take place across the axonal membrane. In addition to specific cell adhesion

12 molecules and cytoskeletal scaffold molecules that maintain the proper function and

13 architecture of nodes (Susuki and Rasband, 2008), these nodes are also the sites of release of

14 several axon-derived signaling molecules that have been shown to regulate the proliferation,

15 differentiation and survival of oligodendrocytes, and control the onset and timing of myelin

16 membrane growth (Simons and Trajkovic, 2006). For example, both the stability and the site-

17 specific translation of MBP mRNA are promoted by the recruitment of the tyrosine kinase Fyn

18 by oligodendrocytic lipid microdomains (White and Kramer-Albers, 2014), and its activation

19 occurs in response to the binding of the axonal cell adhesion molecule L1 (White et al., 2008).

20 Interestingly, the myelin membrane protein TPO1, which has also been proposed to activate

21 Fyn, is highly enriched both in the Golgi and in the Fyn-positive sheets of myelinating

22 oligodendrocytes (Fukazawa et al., 2006; Jain and Ganesh, 2016). Thus, the fine regulation of

23 myelin formation and maintenance appear to depend on trafficking through the Golgi-

24 dependent secretory pathway and microtubule network and signaling pathways in both

25 oligodendrocytes and the neurons, and on their functional interactions at specific sites. 


\subsection{Role of the Golgi apparatus in autophagy}

Autophagy or "self-eating" is an evolutionarily conserved catabolic process by which cytosolic contents are delivered to acidic lysosomes for degradation. It serves various purposes: the maintenance of cellular homeostasis by eliminating waste or toxic products and recycling cellular components and nutrients, especially during conditions of starvation, for protection against certain pathogens, as well as the facilitation of cellular remodeling. In contrast to the ubiquitin-proteasome system (which achieves the regulated degradation of individual ubiquitinated proteins), autophagy leads to the bulk degradation of whole organelles and large amounts of proteins. Of the three main types of autophagy - microautophagy, chaperonemediated autophagy and macroautophagy - the last is the best studied, and is characterized by a newly formed "isolation membrane" or "phagophore" that grows to envelop the components to be degraded in a double-walled structure called the autophagosome, which subsequently fuses with the lysosome (for a broad review, see (Feng et al., 2014; Mizushima and Komatsu, 2011)). For this reason, the term "autophagy" is often used to refer specifically to macroautophagy.

In the central nervous system with its specialized long-lived cells characterized by extensive membrane processes, in addition to its traditional role in maintaining cellular homeostasis (Hu et al., 2015; Tooze and Schiavo, 2008), autophagy plays several other roles: the modulation of synaptic plasticity (Hernandez et al., 2012), the maintenance of the pool of neural stem cells required for postnatal neurogenesis (Wang et al., 2013), and finally, the normal development of the CNS, including neural progenitor proliferation, neuronal maturation, connectivity and myelination (Ban et al., 2013; Hara et al., 2006; Jang et al., 2015; Kadir et al., 2016; Kim et al., 2016; Komatsu et al., 2006; Liang et al., 2010; Rangaraju et al., 2010; Schwarz et al., 2012; Smith et al., 2013; Song et al., 2008). As could be expected, defects in autophagy-related genes or dysfunctions of autophagy are reflected in a number of human neurological disorders (for review, see (Bockaert and Marin, 2015; Ebrahimi-Fakhari et al., 2016; Yamamoto and Yue, 2014)). 
Despite the fact that neurons were among the first cell types in which autophagosomes were

2 observed (Dixon, 1967; Holtzman and Novikoff, 1965), most of the research into the

3 mechanisms of autophagy has focused on other cell types and/or non-mammalian species.

4 However, keeping in mind the highly conserved nature of this process, there is evidence from

5 neuronal and non-neuronal models to show that, at the structural level, the nucleation and the

6 elongation of the phagophore or isolation membrane might occur directly from the Golgi

7 apparatus, although, depending on the cell type involved, the ER or the ERGIC have been

8 proposed as alternative sources (Ge et al., 2015; Lamb et al., 2013). In alternative forms of

9 autophagy (Atg5/Atg7-independent autophagy (Nishida et al., 2009) or the recently discovered

10 Golgi membrane-associated degradation (Yamaguchi et al., 2016)), autophagosomes have been

11 shown to bud directly from Golgi membranes. Using 3D electron tomography of cryopreserved

12 brain tissue, Fernandez-Fernandez et al. have further described distinct engulfing Golgi

13 structures as a potential site for the degradation of cytoplasmic contents in neurons (Fernandez-

14 Fernandez et al., 2017). At the functional level also, there are numerous links between Golgi-

related proteins and autophagic processes. Beclin1 is involved in endosome-to-Golgi recycling

but also plays a crucial early role in autophagosome formation (reviewed in (He and Levine,

17 2010)). The membrane-bound protein Atg9, normally involved in TGN-to-endosome transport,

18 is found in vesicles that contribute to autophagosome formation (Longatti et al., 2012), and the

19 regulation of its trafficking plays a crucial role in the induction of autophagy pathways (Young

20 et al., 2006; Zhou et al., 2017). The clathrin adaptor proteins AP1/2, involved in the clathrin

21 coating of secretory vesicles and known to interact with Atg9, are also necessary for

22 autophagosome formation at specific TGN domains (Guo et al., 2012). UVRAG (UV radiation

23 resistance-associated gene), which normally mediates Golgi-to-ER retrograde transport through

24 the tethering of COPI-coated vesicles, is dissociated from the ER and used for the generation of

25 autophagosomes during autophagy (He et al., 2013). As discussed further below, several Golgi-

26 associated RAB GTPases and their partners, involved in various stages of trafficking, also play 
1 key roles in the formation of the autophagosome (Geng et al., 2010; Itoh et al., 2008; Longatti et al., 2012; Oda et al., 2016; Wen et al., 2017) (see also Table I). In addition, SNAREs

3 (soluble $N$-ethylmaleimide-sensitive fusion protein attachment proteins), small membranebound protein labels that help target vesicles to the Golgi apparatus, are also involved in the fusion of autophagosomes (reviewed in (Reggiori and Ungermann, 2017)). It appears thus that the membrane trafficking role of the Golgi apparatus and its role in autophagy are two sides of the same coin, with the molecular machinery involved in one function being requisitioned to serve the other according to cellular needs.

\subsection{Role of Golgi-associated RAB proteins in the brain}

13

RAB proteins are small GTPases that regulate the docking of cargo vesicles to their target compartments through specific interactions with tether, motor, and coat proteins at almost every step of membrane trafficking, and in both anterograde (secretory) and retrograde (endocytic and recycling) pathways. RAB proteins are considered to be molecular switches, cycling between an active form (bound to GTP) and an inactive form (bound to GDP). The switching between the two forms is regulated by guanine nucleotide exchange factors (GEFs), which promote the active GTP-bound state, and by GTPase-activating proteins (GAPs), which inactivate RABs by promoting hydrolysis of GTP to GDP (Barr and Lambright, 2010). Among the 60 RAB GTPases identified so far in mammalian cells, 20 have been localized to the Golgi complex (Golgi-associated RABs) and 12 appear to be enriched in TGN membranes or to act between the TGN and recycling endosomes (Table I).

Golgi-associated RABs play critical roles in two tightly linked processes that jointly contribute to Golgi homeostasis - Golgi structural organization and membrane trafficking - as the maintenance of ribbon organization is essential for cargo proteins to be correctly modified and efficiently sorted (Liu and Storrie, 2012). An increasing number of studies show that each Golgi-associated RAB fulfils more than one function and can recruit a large number of 
1 effectors in several different locations of the Golgi apparatus. Interestingly, many RABs,

2 including several that are associated with the Golgi apparatus, appear to play a role in the

3 morphogenesis or function of post-mitotic neurons, for example by promoting neurite

4 elongation and/or enhancing dendritic growth and branching in neuronal cultures (Villarroel-

5 Campos et al., 2014). The involvement of some of these Golgi-associated RABs in the

6 autophagic pathway could also be important for the maturation and maintenance of post-mitotic

7 neurons and glia, as mentioned in the previous section (see also Table I). The flip side of this

8 observation is that defects in some of these RABs or their effectors could be expected to lead to

9 the abnormal morphogenesis or function of post-mitotic neurons, as seen for instance in

10 disorders characterized by POM. This is precisely the case with RAB6, RAB1, RAB18,

11 RAB33 and RAB39, which we will examine further below.

12

RAB6 is one of the most abundant and best-characterized Golgi-associated RABs (Goud, 2012). The RAB6 subfamily consists of 4 different isoforms, RAB6A, RAB6A', RAB6B and RAB6C. RAB6A and A', two isoforms encoded by the same gene, localize to the medial and trans-Golgi cisternae, cytoplasmic vesicles and TGN, and can recruit at least 15 different effectors through which they regulate Golgi vesicle biogenesis (Miserey-Lenkei et al., 2010), vesicle tethering at the Golgi (Short et al., 2002), intra-Golgi transport and retrograde transport from late endosomes via the Golgi to the ER (Heffernan and Simpson, 2014). Recent studies, however, suggest that the main function of RAB6 is to ensure the generation of postGolgi carriers and their exocytosis (Grigoriev et al., 2007; Grigoriev et al., 2011). Nevertheless, in the context of microcephaly, the role of RAB6 in regulating retrograde transport and its functional interactions with other molecules involved in this process, RAB33B and the COG complex (Starr et al., 2010; Sun et al., 2007), are particularly intriguing (see next section). A second gene encodes the brain-specific isoform RAB6B, which is localized to structures similar to RAB6A/A', but is preferentially expressed in neuronal cells (Opdam et al., 
1 2000), where it also mediates retrograde membrane transport in neurites (Opdam et al., 2000;

2 Wanschers et al., 2007); however, whether this transport also involves the Golgi-to-ER

3 compartment has not been confirmed. Interestingly, RAB6A/A' and B are thought to play a key

4 role in the regulation of neurite outgrowth during the early phase of neuronal differentiation,

5 through the recruitment Bicaudal-D-related protein 1 and dynamic interactions with the kinesin

6 motor Kif1C and the dynein/dynactin retrograde motor complex (Schlager et al., 2010).

7 RAB6C is encoded by a primate-specific intronless gene and is expressed in a limited number

8 of human tissues (including brain). In contrast to other RAB6 proteins, RAB6C associates with

9 the centrosome and is involved in cell cycle progression (Young et al., 2010).

RAB1 is known to regulate anterograde membrane trafficking mediated by vesicles

11 coated with the coatomer COPII between the ER and the Golgi, where its two isoforms RAB1A

12 and RAB1B are predominantly expressed (Plutner et al., 1991; Saraste et al., 1995), but it is 13 also present in lipid microdomains and in autophagosomes (Wang et al., 2010; Zoppino et al., 2010). As for RAB6, RAB1 can recruit many different effectors such as the golgins p115, GM130, GIANTIN, GRASP65 and GOLGIN-84, which act as tethers to help COPII-coated vesicles dock to cis-Golgi membranes (Alvarez et al., 2001; Diao et al., 2003; Moyer et al., 2001; Satoh et al., 2003; Weide et al., 2001). Interestingly, Drosophila neurons lacking a functional dar6 gene (the Drosophila RAB1 homolog) show reduced dendritic arborization (Ye et al., 2007). Conversely, over-expression of RAB1 rescues defective vesicular trafficking in models of Parkinson disease with $\alpha$-Synuclein-induced disruption of ER-to-Golgi transport

21 (Cooper et al., 2006). This suggests that RAB1 is critical to both neuronal differentiation and homeostasis.

RAB18, although less well studied, appears to have multiple roles as well, depending on cell type and differentiation stage, and a combination of effectors (Vazquez-Martinez and 25 Malagon, 2011). In certain non-neuronal cells, e.g. adipocytes and hepatic stellate cells, RAB18 is associated with lipid droplets and functions in cell activation and lipid metabolism (Martin et 
1 al., 2005; O'Mahony et al., 2015; Ozeki et al., 2005). In neuroendocrine cells, RAB18 cycles

2 between the cytosol and the surface of a discrete population of secretory granules to reduce

3 their transport, and thereby negatively modulates the secretory activity of the cells (Vazquez-

4 Martinez et al., 2007). In most cells, RAB18 is also present in the cis-Golgi and ER compartments (Dejgaard et al., 2008) and is required to maintain the morphology of the

6 perinuclear ER (Gerondopoulos et al., 2014). There is good evidence that RAB18 can bind the

7 ER-resident Ds11 protein complex (Gillingham et al., 2014), which tethers and fuses vesicles returning from the Golgi. This suggests that RAB18 may participate in the tethering of COPIcoated vesicles to the ER (Gillingham et al., 2014; Schroter et al., 2016). Interestingly, RAB18 is expressed in the developing mouse brain from E14.5, and its expression markedly increases around birth (Wu et al., 2016). The depletion of RAB18 impairs the radial migration of neurons to the cortical plate in vivo and alters cortical neuron morphogenesis in vitro (Wu et al., 2016), providing evidence that $\mathrm{RAB} 18$ is critical to neuronal positioning and maturation. related and conserved proteins encoded by distinct genes, $R A B 33 A$ and $R A B 33 B$. Both are Golgi-associated proteins but RAB33A is found only in the brain, lymphocytes and melanocytes (Cheng et al., 2006; Lee et al., 2006; Zheng et al., 1997), whereas RAB33B is ubiquitous (Zheng et al., 1998). In the mouse brain, RAB33A is particularly highly expressed throughout all cell layers of the cortex and hippocampus (Cheng et al., 2006). In neurons, the protein preferentially accumulates in growing axons and is found both in Golgi membranes and in synaptophysin-positive vesicles that are transported along the growing axons (Nakazawa et al., 2012). RAB33A downregulation inhibits the anterograde axonal transport of these vesicles while its overexpression results in their excessive accumulation and the formation of supernumerary axons (Nakazawa et al., 2012), suggesting that RAB33A mediates axonogenesis and anterograde axonal transport of post-Golgi vesicles. Although RAB33B 
1 perfectly conserved), functional studies have assigned a role for RAB33B in the regulation of

2 the retrograde transport of vesicles between the Golgi and the ER (Starr et al., 2010).

3 Interestingly, RAB33B and RAB6A cooperate in regulating Golgi-to-ER trafficking and are

4 thought to act through a common $\mathrm{RAB}$ cascade in which the active form RAB33B recruits the

5 GEFs necessary to activate RAB6A (Pusapati et al., 2012). In addition, RAB33B plays a role in

6 autophagy by modulating autophagosome formation through an interaction with Atg16L (Ao et 7 al., 2014).

Like RAB33B, RAB39B is a neuron-specific protein that is localized to the Golgi apparatus (Giannandrea et al., 2010). Interestingly, both its downregulation and overexpression in mouse primary hippocampal neurons significantly affect neuronal branching, the density of 11 presynaptic boutons and subsequent synapse formation (Giannandrea et al., 2010; Vanmarsenille et al., 2014; Wilson et al., 2014). This suggests that the tightly tuned expression of RAB39B is required for proper neuronal maturation and further illustrates the direct link between Golgi-associated RABs and the specification and maintenance of post-mitotic neurons.

\section{Syndromes with postnatal onset microcephaly (POM) and causative genes}

\subsection{Postnatal-onset microcephaly}

Postnatal-onset microcephaly (POM) reflects a failure of the brain to achieve its normal growth after birth, implicating mechanisms occurring during infancy or childhood and involved in its maturation rather than those involved in its formation. At birth, the human brain is only at around $60 \%$ of its adult size. The processes critical to ensure the establishment of a functional neuronal network largely take place postnatally, throughout childhood, adolescence and even into adulthood (Figure 2): while most neurons are produced and migrate during corticogenesis (i.e. during the first two trimesters), synaptogenesis, which starts at mid-gestation, massively 
1 trimester, increases in childhood and lasts until adulthood. Similarly, the myelination process,

2 by which oligodendrocytes enwrap axons to generate a myelin sheath, starts during the third

3 trimester of gestation and peaks around two to three years of age, but persists throughout

4 childhood and adolescence and continues into adulthood (Back et al., 2002; Bercury and

5 Macklin, 2015). In line with this prolonged role of glial cells, gliogenesis, though very active

6 around 32-40 weeks of gestation, largely continues after birth, especially during the first two

7 years of life (Stiles and Jernigan, 2010). POM, which likely results from the impairment of one

8 or several of these maturation processes, thus consistently becomes apparent during the first

9 two years of age (Figure 2). In most cases, POM is associated with cognitive impairments of

variable severity and outcome, collectively referred as to intellectual disability. Regardless of

11 the pathophysiological mechanism involved, as for primary microcephaly, POM has multiple

12 etiologies that may be genetic or environmental. A good classification has been proposed in the

13 review by Ashwal and colleagues (Ashwal et al., 2009), and distinguishes, among the genetic causes of POM, inborn errors of metabolism from the syndromic forms of POM.

The most famous syndrome consistently associated with POM is undoubtedly Rett syndrome (RTT). Among the many neurological and behavioral features that characterize the 17 complex clinical spectrum of this neurodevelopmental disorder, typical criteria include a 18 normal period of development followed by a deceleration of head growth in the first two years of life, associated with cognitive deterioration and seizures (Liyanage and Rastegar, 2014; Pohodich and Zoghbi, 2015). Neuropathological examinations reveal reduced cortical thickness associated with smaller and more closely packed neuronal cell bodies, but no active neurodegeneration (Bauman et al., 1995). Local myelin abnormalities and abnormal membrane-bound inclusions in oligodendrocytes have also been reported in several RTT cases, suggesting an involvement of white matter defects in the microcephaly associated with RTT patients (Lekman et al., 1991; Papadimitriou et al., 1988). MeCP2, the major RTT gene, 
1 transcriptional repressor to modulate the transcription of target neuronal genes (Ausio et al.,

2 2014), MeCP2 has turned out to be a multifunctional protein with many interactors and several

3 roles in the CNS. It is expressed in microglia, astrocytes and oligodendrocytes in addition to

4 neurons (Cronk et al., 2016), and is located in cellular compartments other than the nucleus,

5 such as the cytosol (Miyake and Nagai, 2007), the post-synaptic compartments of neurons

6 (Aber et al., 2003) and even the centrosome (Bergo et al., 2015). In line with this, a role for

$7 \mathrm{MeCP} 2$ in microtubule stability and vesicular transport has been suggested recently (Delepine

8 et al., 2013; Roux et al., 2012).

9

\subsection{Golgi-associated proteins implicated in POM}

Vesicular routing within the cell is highly dependent on microtubules, and the Golgi apparatus is central to this process as it not only drives translational modifications of freshly synthesized proteins and lipids but also orchestrates the complex process that allows them to be packed into specific transport vesicles and routed to their final destinations (Boncompain and Perez, 2013b). As detailed in the introduction, this is even more relevant in the case of neurons and oligodendrocytes. In line with the involvement of the secretory pathway in brain maturation, an increasing number of genes that have been recently associated with syndromic or isolated POM appear to encode Golgi proteins involved in the regulation of the Golgimediated traffic machinery, including vesicle targeting and membrane recycling (Table II).

\subsubsection{Cohen syndrome and COH1/VPS13B}

Cohen syndrome (COH, MIM 216550) is an autosomal recessive disorder characterized by motor delays, retinal dystrophy appearing by mid-childhood, progressive severe myopia, hypotonia, joint hypermobility and progressive POM associated with intellectual disability (Wang et al., 1993). Brain MRI reveals a relatively large corpus callosum in some patients, associated with markedly smaller sagittal diameters of the brain stem (Kivitie-Kallio et al., 
1 1998). While the neurological signs are most prominent, additional features such as short

2 stature, small hands and feet or childhood-onset obesity have also been reported in some

3 patients but are not constant (Falk et al., 2004). COH1, the only gene associated with Cohen

4 syndrome so far, encodes VPS13B, a large peripheral membrane protein that displays regions

5 homologous to yeast vacuolar protein sorting-associated protein 13 (Vps13p), and is active in

6 the Golgi (Seifert et al., 2011). VPS13B has recently been found to colocalize and interact

7 physically with the active form of RAB6 (Seifert et al., 2015). Depletion experiments using

8 RNAi against RAB6 show that it is required for VPS13B recruitment to Golgi membranes.

9 Conversely, the downregulation of VPS13B or a blockade of its recruitment to the Golgi

10 apparatus results in the fragmentation of Golgi ribbons and a simultaneous inhibition of neurite

11 outgrowth in hippocampal neurons (Seifert et al., 2011; Seifert et al., 2015). Thus, the gene

12 responsible for Cohen syndrome likely encodes an effector protein of RAB6 with a specific

13 role in the dynamics and function of the Golgi apparatus in particular during neuronal 14 maturation (Figure 1B). Hypoplasia type 2E (PCCA2/PCH2E, MIM 615851) is an autosomal recessive neurodegenerative disorder characterized by normal development during the first three to five months of life, followed by motor delays, progressive POM, progressive spasticity leading to contracture and epileptic seizures prior to two years of age (Ben-Zeev et al., 2003). Patients have a normal head circumference at birth and undergo progressive growth deceleration, resulting in microcephaly during the first year of life. Brain MRI reveals a gradual decrease in cerebral white matter associated with delayed myelination and thinning of the corpus callosum (Ben-Zeev et al., 2003). The responsible gene, mapped and identified in 2014, encodes VPS53, 
1 derived transport vesicles (Feinstein et al., 2014). VPS53 is part of two large multisubunit

2 complexes named Golgi-associated retrograde protein (GARP) and Endosome-associated

3 recycling protein (EARP). Both GARP and EARP ensure the proper tethering between

4 endosomes and their acceptor compartment. GARP is a peripheral complex associated with the

5 TGN and is involved in tethering retrograde transport carriers from endosomes to the TGN

6 (Bonifacino and Hierro, 2011). EARP, characterized more recently, is localized to recycling

7 endosomes and promotes their fast recycling back to the plasma membrane (Schindler et al.,

8 2015). Both complexes cooperate with SNAREs for subsequent membrane fusion. RAB

9 proteins play an essential role during these tethering-fusion steps as they recruit the required

10 tethering factors. In line with this role, GARP has been found to interact with RAB6A at the

11 TGN (Liewen et al., 2005) and EARP associates with RAB4-containing vesicles (Schindler et

12 al., 2015). Thus, the gene responsible for PCCA2 syndrome encodes a subunit of tethering

13 complex proteins that specifically interact with RAB GTPases during endosomal transport in 14 between the TGN and the plasma membrane (Figure 1B).

\subsubsection{Warburg-Micro syndrome and RAB3GAP1/2, RAB18 and TBC1D20}

Warburg-Micro syndrome (WARBM1, MIM 600118) is an autosomal recessive disorder characterized by neurodevelopmental defects, severe visual impairment and hypogonadism (Warburg et al., 1993). Neurodevelopmental features generally include POM with profound intellectual disability and progressive limb spasticity associated with progressive peripheral axonal neuropathy (Bem et al., 2011). Brain MRI shows predominantly frontal polymicrogyria bilaterally, and hypoplasia of the corpus callosum and cerebellar vermis (Handley et al., 2013; Liegel et al., 2013). Loss-of-function mutations in four distinct genes, RAB3GAP1, RAB3GAP2, RAB18 and TBC1D20, have been implicated in WARBM1 in recent years (Aligianis et al., 2005; Borck et al., 2011; Liegel et al., 2013). RAB18 has been linked to several distinct membrane-bound organelles such as endosomes (Lutcke et al., 1994), 
1 peroxisomes (Gronemeyer et al., 2013), secretory granules (Vazquez-Martinez et al., 2007) and

2 the ER, and to lipid droplet formation (Martin et al., 2005; Ozeki et al., 2005), depending upon

3 circumstances and cell types. More recent studies have confirmed its localization in the ER and

4 the cis-Golgi compartment (Dejgaard et al., 2008). The RAB3GAP complex, initially identified

5 as a GTPase activating protein (GAP) specific to the RAB3 subfamily of small G proteins

6 (Fukui et al., 1997; Nagano et al., 1998), is also a GEF (guanine nucleotide exchange factor) of

7 RAB18 (Gerondopoulos et al., 2014). TBC1D20, an ER-localized GAP that promotes the 8 hydrolysis of RAB1 GTP (Haas et al., 2007; Sklan et al., 2007), is thought to act on RAB18 as 9 well (Handley et al., 2015). Thus, RAB3GAP1, RAB3GAP2 and TBC1D20 all play a role in the regulation of the RAB18 activity, directly linking WARBM1 to RAB18 deficiency or 11 dysregulation. RAB3GAP and TBC1D20 also regulate the ER localization of RAB18, an 12 essential step to support the function of RAB18 in the control of ER structural integrity and 13 retrograde membrane recycling from the Golgi apparatus to the ER (Gerondopoulos et al., 2014; Handley et al., 2015). Thus, the genes involved in WARBM1 all pinpoint a specific RAB-dependent pathway directly associated with ER-Golgi trafficking (Figure 1B).

Loss-of-function mutations in the TRAPPC 9 gene were originally identified by autozygosity mapping in four families with a nonsyndromic autosomal recessive intellectual disability (MRT13, MIM 613192) (Mir et al., 2009; Mochida et al., 2009; Philippe et al., 2009). Since then, 3 additional cases have been reported. Although initially referred to as nonsyndromic, the phenotype that is starting to emerge appears to be quite distinctive, including moderate to severe POM, a peculiar facial appearance, obesity and hypotonia. Reported brain anomalies consistently include a reduced volume of the cerebral white matter with a hypersignal on FLAIR sequences, and a marked thinning of the corpus callosum (Abou 
1 of the Trafficking Protein Particle (TRAPP) complex, which mediates the tethering of COPII-

2 coated ER-derived vesicles to allow their fusion with cis-Golgi membranes (Barrowman et al.,

3 2010). The TRAPP complex acts through the recruitment and activation of the GTPase RAB1,

4 which in turn recruits specific cis-Golgi effectors such as p115 and GM130, allowing the

5 tethering of the vesicles to Golgi membranes (Barnekow et al., 2009). During this anterograde

6 ER-to-Golgi transport, the TRAPP complex is dynamically associated with the microtubules

7 through a physical interaction with $\mathrm{p} 150^{\mathrm{Glued}}$, a subunit of dynactin. A recent study has

8 proposed that TRAPPC9 in particular mediates the interaction between $\mathrm{p} 150^{\mathrm{Glued}}$ and COPII-

9 coated vesicles until they reach their target membrane (Zong et al., 2012), evoking an

10 additional paradigm in which RAB-associated ER-Golgi trafficking linked to POM and white

11 matter defects (Figure 1B).

12

\subsubsection{A neuromuscular syndrome with microcephaly and GOLGA2/GM130}

A homozygous frame-shift deletion in the GOLGA2 gene that results in a loss of gene function has recently been identified in an individual with a neuromuscular phenotype characterized by developmental delays, seizures, progressive microcephaly starting at 4 months of age, hypotonia and muscular dystrophy (Shamseldin et al., 2016). Here also, brain MRI has revealed delayed myelination and a thinning of the corpus callosum, but with no other specific loss of cerebral volume. GOLGA2 encodes the Golgi matrix protein GM130, which is a peripheral membrane protein located on the cis-side of the Golgi apparatus and involved in both the assembly/maintenance of Golgi structure and the regulation of the secretory pathway (Nakamura, 2010). As mentioned above in the case of TRAPPC9, GM130 participates in membrane-tethering events at the Golgi complex through dynamic interactions with RAB1 and other tethering proteins such as p115, to ensure efficient anterograde cargo delivery to the cisGolgi compartment. Moreover, GM130 binds to other RAB proteins involved in membrane traffic regulation at the ER/Golgi interface, such as RAB2 and RAB33B (Short et al., 2001; 
1 Valsdottir et al., 2001). Thus, GOLGA2/GM130 deficiency appears to be yet another situation

2 highlighting the link between Golgi-associated RABs, POM and white matter defects (Figure 3 1B).

4

\subsubsection{Dyggve-Melchior-Clausen syndrome and DYMECLIN}

Dyggve-Melchior-Clausen syndrome (DMC, MIM \#223800) is an autosomal recessive skeletal dysplasia associated with POM and intellectual disability, and caused by loss-offunction mutations in the DYM gene encoding DYMECLIN, a Golgi protein involved in intracellular trafficking (Dimitrov et al., 2009; Osipovich et al., 2008; Paupe et al., 2004). Brain MRI in DMC patients with a truncating mutation in DYM reveals a marked thinning of the corpus callosum and brain stem (Dupuis et al., 2015). In line with this finding, recent data from our group show a significant reduction in white matter volume associated with defects in the way the myelin sheath is wrapped, and a reduced thickness of myelinated axons in Dym-/mutant mice (Dupuis et al., 2015). Interestingly, Dym-deficient neurons display a fragmented Golgi apparatus and impaired ER-to-Golgi trafficking (Dupuis et al., 2015). However, an impairment of the retrograde transport of vesicles from the Golgi to the ER has also been suggested in Dym-/- mouse embryonic fibroblasts (Osipovich et al., 2008). Although DYMECLIN function is still elusive at the molecular level, several lines of evidence suggest that it has a tethering role during vesicle trafficking between the ER and the Golgi: (i) DYMECLIN localizes to both the cytosol and the periphery of cis-Golgi membranes, and permanently shuttles between these two compartments (Dimitrov et al., 2009), (ii) DYMECLIN colocalizes and directly interacts with GIANTIN (Dimitrov et al., 2009; Osipovich et al., 2008), a giant Golgi-resident protein of the golgin family that forms complexes with RAB1 or RAB6 to tether Golgi membranes with membrane structures derived from the ER (anterograde pathway) or returning to the ER (retrograde pathway), respectively (Goud and Gleeson, 2010; Koreishi et al., 2013; Rosing et al., 2007) (Figure 1B). 
1 Interestingly, Smith McCort dysplasia, a clinical variant of DMC syndrome with identical

2 skeletal defects but normal intelligence and no microcephaly, has been found to result either

3 from specific missense mutations in DYM that could result in some residual activity of the

4 protein (SMC1, MIM \#607326) (Cohn et al., 2003; Dimitrov et al., 2009) or from loss-of-

5 function mutations in the small GTPase RAB33B (SMC2, MIM \#615222) (Alshammari et al.,

6 2012; Dupuis et al., 2013). Given that the main functional domains of RAB33A and RAB33B

7 proteins are perfectly conserved (Zheng et al., 1998), it is tempting to speculate that the

8 cerebral phenotype in SMC is rescued by the partial activity of DYMECLIN (SMC1) or a

9 complementation of RAB33B deficiency by RAB33A in the brain (SMC2). Interestingly, both

RAB33A and RAB33B are present in the Golgi complex (Cheng et al., 2006; Zheng et al.,

11 1998) and are involved in the regulation of vesicular transport: while RAB33B functions in

12 concert with RAB6 to coordinate bidirectional intra-Golgi and retrograde Golgi-to-ER transport

13 (Starr et al., 2010), RAB33A has been shown to mediate the anterograde transport of post-

14 Golgi vesicles in growing hippocampal axons (Nakazawa et al., 2012). Although the precise link between DYM, RAB33A/B and RAB6 is yet to be understood, these factors likely function in the regulation of common Golgi-driven secretory pathways.

17

\subsubsection{Congenital disorders of glycosylation and the COG complex}

Congenital Disorders of Glycosylation (CDG) represent a huge and still growing family of multisystemic autosomal recessive pathologies involving dysfunctions in the processing of $\mathrm{N}$ - and O-linked glycans, with most of the genes identified so far encoding glycosylation enzymes (Freeze and $\mathrm{Ng}, 2011$ ). However, one subgroup of these diseases involves the Conserved Oligomeric Golgi (COG) complex, a hetero-octameric protein complex, which, as its name suggests, is localized to the cis and medial Golgi as well as surrounding vesicles (Climer et al., 2015). The COG complex is thought to act as a tethering factor, in particular during intra-Golgi and retrograde Golgi-to-ER trafficking, where it mediates the recycling of 
1 Golgi glycosyltransferases (Shestakova et al., 2006). Loss-of-function mutations in seven of the

2 eight COG subunits have been associated with CDG, possibly due to the accumulation of COG

3 complex-dependent vesicles, likely resulting in the segregation of Golgi glycosylation enzymes

4 from their target proteins (Climer et al., 2015). Mutations affecting the COG complex thus

5 result in multiple protein glycosylation deficiencies. Among the many neurological

6 manifestations described in COG-associated CDG, POM has been reported in patients carrying

7 mutations in COG1, COG2, COG7 and COG8 (Foulquier et al., 2007; Foulquier et al., 2006;

8 Kodera et al., 2015; Morava et al., 2007). In addition, hypoplasia of the corpus callosum has

9 been observed on brain MRI in four patients (Kodera et al., 2015; Morava et al., 2007) and

10 brainstem atrophy has been reported in one case (Foulquier et al., 2007). Interestingly, the

11 COG complex has been shown to interact with molecules at all levels of Golgi organization and

12 trafficking, including several Golgi-associated SNAREs (Laufman et al., 2013a; Laufman et

13 al., 2011, 2013b; Laufman et al., 2009; Shestakova et al., 2007), golgins such as p115, GM130,

14 GIANTIN and GOLGIN-84 (Miller et al., 2013; Shestakova et al., 2007; Sohda et al., 2010;

15 Sohda et al., 2007), vesicular coatomers such as COPI, and molecular motors (Kristensen et al.,

16 2012; Miller et al., 2013) as well as a number of Golgi-associated RABs. Among the latter are

$17 \mathrm{RAB} 1 \mathrm{~A} / \mathrm{B}, \mathrm{RAB} 2 \mathrm{~A}, \mathrm{RAB} 6 \mathrm{~A} / \mathrm{B}, \mathrm{RAB} 10, \mathrm{RAB} 14, \mathrm{RAB} 30, \mathrm{RAB} 36, \mathrm{RAB} 39$ and RAB41

18 (reviewed in (Willett et al., 2013)), again pointing to the relationship between defects in these

19 functionally important Golgi-associated proteins on the one hand, and POM and white matter

20 defects on the other (Figure 1B).

21 


\section{Possible mechanisms underlying postnatal microcephaly}

3

A consistent finding in all the disorders described above is the presence of white matter defects, and in particular of abnormalities of the corpus callosum, which, thanks to its relatively high visibility in live imaging modalities as well as conventional histology, could rightly be considered a window into the diseased brain. Although white matter, which is made up of millions of axon bundles that interconnect neurons throughout the brain into functional circuits, accounts for half the volume of the human brain, its role in brain maturation and homeostasis is still far less studied than that of the cortex. Yet, it is essential for impulse conduction, and is thought to participate actively in higher functions such as learning, reasoning (in particular mathematical thinking (Matejko and Ansari, 2015)), and memory (Fields, 2010). Consistent with this broad involvement, axonal transport defects are now being described in an increasing number of degenerative disorders such as Alzheimer's and Parkinson's diseases, amyotrophic lateral sclerosis, Charcot-Marie-Tooth disease and hereditary spastic paraplegia etc. (Duncan and Goldstein, 2006; Neefjes and van der Kant, 2014). The fragmentation and dispersal of the Golgi apparatus has been documented as an early event in these degenerative processes (Gonatas et al., 2006; Haase and Rabouille, 2015; Joshi et al., 2015), and the Golgi, in addition to being a sensor of stress signals in cell death pathways (Machamer, 2015; Nakagomi et al., 2008), may be actively involved in degeneration (Rabouille and Haase, 2015).

However, defective Golgi trafficking is not only an important issue in neurodegenerative conditions but during development, including in predominantly postnatal processes such as the maturation of white matter, as indicated by its involvement in POM highlighted in the present review. The demand for secretory traffic increases exponentially as axons elongate, dendrites multiply and myelination increases. If even a single link in the supply chain is deficient, whether in neurons or the oligodendrocytes that myelinate them, the Golgi apparatus likely detects this stress, which, beyond a certain threshold, becomes detrimental and affects cell 
1 maturation and maintenance. Additionally, in many cases of POM, as detailed above, the

2 deficient link appears to be none other than a member of the Golgi-mediated secretory traffic

3 machinery. The implication of several Golgi-associated RABs in the pathophysiology of POM

4 highlights the central role of the Golgi apparatus in dynamically receiving and generating

5 specific membrane vesicles both in large quantities and in a highly controlled manner. Thus,

6 one possible mechanism responsible for the development of POM could be an insufficient

7 supply of synaptic and/or oligodendrocytic cargos due to a defective secretory pathway in these

8 highly demanding cells (Dupuis et al., 2015). Such a defect may be due to ineffective transport,

9 alteration in cargo maturation (e.g. glycosylation, proteolysis) or problems in routing to the proper target compartment. Defective secretory trafficking combined with hypomyelination

11 likely leads to an impairment of synaptic transmission, contributing to the intellectual disability 12 observed in POM patients and perhaps further weakening diseased neurons. Thus, while POM 13 or acquired microcephaly is not traditionally considered a disorder on its own but rather as a 14 clinical feature present in various genetic syndromes, and several syndromes featuring POM are associated with genes and functions that do not directly involve membrane trafficking 16 (Seltzer and Paciorkowski, 2014), we believe that there exists a distinct subset of POM with 17 similar pathophysiological mechanisms and clinical manifestations. We propose that this 18 distinct and coherent ensemble of causes and effects - defects in Golgi-associated RABs or their partners, altered trafficking of molecules, vesicles and membrane components essential for neuronal and oligodendrocytic activity, the resulting defective myelination and synaptic

21 function and finally, microcephaly with a postnatal onset independent of neural progenitor 22 proliferation or migration - be named "Golgipathic microcephalies".

23 The impairment of autophagic pathways is also likely implicated in the pathophysiology of 24 POM and may be related to defects in the conventional secretory pathway. Among the 25 autophagy-related molecules involved in POM, the tethering complex GARP (of which VPS53, 26 involved in PCCA2, is a subunit) is recruited at the phagophore membrane during 
1 autophagosome assembly (Yang and Rosenwald, 2016). TBC1D20, one of the genes associated

2 with Warburg-Micro syndrome, plays an essential role in the maturation of autophagosomes

3 via its RAB1BGAP function (Sidjanin et al., 2016). RAB33A and B are known to modulate

4 autophagosome formation through their interaction with ATG16L (Itoh et al., 2008). The

5 vesicle-tethering golgin GM130 has also been shown to participate in the regulation of

6 autophagy through dynamic interactions with GABARAP and WAC proteins (Joachim et al.,

7 2015). It is also likely that some syndromes involving defective autophagy do indeed include

8 POM among their symptoms, but that this link has been missed among the multitude of other

9 symptoms involved, or ignored because of a lack of understanding regarding the underlying

cause. For instance, a form of hereditary spastic paraplegia linked to mutations in TECPR2,

11 which regulates COPII-dependent vesicle formation (Stadel et al., 2015), has recently been

12 shown to include progressive microcephaly among its symptoms (Heimer et al., 2016; Oz-Levi

13 et al., 2012), although it is not yet known whether this is due to neurodevelopmental or 14 neurodegenerative processes. As mentioned previously, several other ER/Golgi-associated RAB proteins such as RAB1, RAB11 and RAB24, are also involved in the regulation of 16 autophagy, further highlighting the crosstalk, if not the overlap, between Golgi membrane 17 trafficking and autophagy pathways (Jain and Ganesh, 2016) (Table I).

18 The clinical manifestations of "Golgipathies" may not be restricted to the white matter or myelinated neurons predominantly affected in POM. The Golgi apparatus obviously plays a crucial role in numerous cell types, a fact supported by the diversity of other symptoms 21 displayed by patients with "Golgipathies": stunted growth, neuromuscular dysfunctions, metabolic disorders, pubertal anomalies etc. It is unclear at present in what cells and to what extent Golgi trafficking deficits in other organs and tissues contributes to the phenotype in these syndromes. Besides, with regard to disorders of the autophagic pathway and the putative overlap between the molecular machinery involved in this pathway and that traditionally associated with trafficking, other symptoms that have been overlooked until now may also turn 
1 out to form part of the clinical spectrum. In addition, although neurodegeneration has not been

2 shown to be involved in the types of POM described in the present review, it cannot be ruled 3 out, as the long-term evolution of the cases reported so far is unknown. However, it is worth

4 noting that retinal degeneration has been documented in Cohen syndrome (North et al., 1995),

5 and sensory axon degeneration associated with a deletion of RAB18 has recently been

6 described in a mouse model of Warburg-Micro syndrome (Cheng et al., 2015). Future

7 investigations into POM-related syndromes where the responsible gene has not been identified

8 should therefore be carried out in light of the notion of Golgi trafficking defects as a possible 9 etiology.

\section{Conclusion}

The newly identified defects in certain Golgi-associated proteins, including RABs and their interactors, that we have highlighted in the present review and propose to name 14 "Golgipathic microcephalies" or "Golgipathies", and more broadly, the notion that the primary deregulation of the trafficking machinery is itself a mechanism leading to POM, is clearly an emerging research area that it would be important to investigate in coming years. Future studies in this field will surely improve our understanding of the molecular mechanisms linking Golgi function and the maturation of white matter, in addition to extending the predicted and observed phenotype of patients with these disorders and creating new avenues to optimize cognitive outcome by reversing part of the maturation defects.

\section{Acknowledgements}

We are grateful to Cécile Martel for invaluable support. This work was supported by the Institut National pour la Santé et la Recherche Médicale (INSERM), the Centre National de la Recherche Scientifique (CNRS), the Université Paris 7, DHU PROTECT, and European and 
FP (GENOPAT 2009, DYMension project), ANR-13-RARE-0007-01 to SP and VEG (ERA-

NET E-Rare 2013, EuroMicro project), ANR-15-NEUR-0003-01 to PG (ERA-NET Neuron,

MicroKin project), and ANR-16-CE16-0024-01 to VEG and FP (PRC GENERIQUE 2016,

MicroGol project).

\section{References}

Aber, K.M., Nori, P., MacDonald, S.M., Bibat, G., Jarrar, M.H., Kaufmann, W.E., 2003. Methyl-CpG-binding protein 2 is localized in the postsynaptic compartment: an immunochemical study of subcellular fractions. Neuroscience 116, 77-80.

Abou Jamra, R., Wohlfart, S., Zweier, M., Uebe, S., Priebe, L., Ekici, A., Giesebrecht, S., Abboud, A., Al Khateeb, M.A., Fakher, M., Hamdan, S., Ismael, A., Muhammad, S., Nothen, M.M., Schumacher, J., Reis, A., 2011. Homozygosity mapping in 64 Syrian consanguineous families with non-specific intellectual disability reveals 11 novel loci and high heterogeneity. Eur J Hum Genet 19, 1161-1166.

Aggarwal, S., Yurlova, L., Snaidero, N., Reetz, C., Frey, S., Zimmermann, J., Pahler, G., Janshoff, A., Friedrichs, J., Muller, D.J., Goebel, C., Simons, M., 2011. A size barrier limits protein diffusion at the cell surface to generate lipid-rich myelin-membrane sheets. Dev Cell 21, 445-456.

Ainger, K., Avossa, D., Morgan, F., Hill, S.J., Barry, C., Barbarese, E., Carson, J.H., 1993. Transport and localization of exogenous myelin basic protein mRNA microinjected into oligodendrocytes. The Journal of cell biology 123, 431-441.

Aizawa, M., Fukuda, M., 2015. Small GTPase Rab2B and Its Specific Binding Protein Golgiassociated Rab2B Interactor-like 4 (GARI-L4) Regulate Golgi Morphology. J Biol Chem 290, 22250-22261.

Alcantara, D., O'Driscoll, M., 2014. Congenital microcephaly. American journal of medical genetics. Part C, Seminars in medical genetics 166C, 124-139.

Aligianis, I.A., Johnson, C.A., Gissen, P., Chen, D., Hampshire, D., Hoffmann, K., Maina, E.N., Morgan, N.V., Tee, L., Morton, J., Ainsworth, J.R., Horn, D., Rosser, E., Cole, T.R., Stolte-Dijkstra, I., Fieggen, K., Clayton-Smith, J., Megarbane, A., Shield, J.P., Newbury-Ecob, R., Dobyns, W.B., Graham, J.M., Jr., Kjaer, K.W., Warburg, M., Bond, J., Trembath, R.C., Harris, L.W., Takai, Y., Mundlos, S., Tannahill, D., Woods, C.G., Maher, E.R., 2005. Mutations of the catalytic subunit of RAB3GAP cause Warburg Micro syndrome. Nat Genet 37, 221-223.

Alshammari, M.J., Al-Otaibi, L., Alkuraya, F.S., 2012. Mutation in RAB33B, which encodes a regulator of retrograde Golgi transport, defines a second Dyggve-Melchior-Clausen locus. J Med Genet 49, 455-461.

Alvarez, C., Garcia-Mata, R., Hauri, H.P., Sztul, E., 2001. The p115-interactive proteins GM130 and giantin participate in endoplasmic reticulum-Golgi traffic. J Biol Chem 276, 2693-2700.

Amaya, C., Militello, R.D., Calligaris, S.D., Colombo, M.I., 2016. Rab24 interacts with the Rab7/RILP complex to regulate endosomal degradation. Traffic.

Anitei, M., Hoflack, B., 2011. Exit from the trans-Golgi network: from molecules to mechanisms. Curr Opin Cell Biol 23, 443-451.

Ao, X., Zou, L., Wu, Y., 2014. Regulation of autophagy by the Rab GTPase network. Cell Death Differ 21, 348-358. 
Ashwal, S., Michelson, D., Plawner, L., Dobyns, W.B., Quality Standards Subcommittee of the American Academy of, N., the Practice Committee of the Child Neurology, S., 2009. Practice parameter: Evaluation of the child with microcephaly (an evidence-based review): report of the Quality Standards Subcommittee of the American Academy of Neurology and the Practice Committee of the Child Neurology Society. Neurology 73, 887-897.

Ausio, J., Martinez de Paz, A., Esteller, M., 2014. MeCP2: the long trip from a chromatin protein to neurological disorders. Trends in molecular medicine 20, 487-498.

Baas, P.W., 1999. Microtubules and neuronal polarity: lessons from mitosis. Neuron 22, 23-31.

Back, S.A., Luo, N.L., Borenstein, N.S., Volpe, J.J., Kinney, H.C., 2002. Arrested oligodendrocyte lineage progression during human cerebral white matter development: dissociation between the timing of progenitor differentiation and myelinogenesis. $J$ Neuropathol Exp Neurol 61, 197-211.

Ban, B.K., Jun, M.H., Ryu, H.H., Jang, D.J., Ahmad, S.T., Lee, J.A., 2013. Autophagy negatively regulates early axon growth in cortical neurons. Mol Cell Biol 33, 39073919.

Barnekow, A., Thyrock, A., Kessler, D., 2009. Chapter 5: rab proteins and their interaction partners. International review of cell and molecular biology 274, 235-274.

Barr, F., Lambright, D.G., 2010. Rab GEFs and GAPs. Curr Opin Cell Biol 22, 461-470.

Barrowman, J., Bhandari, D., Reinisch, K., Ferro-Novick, S., 2010. TRAPP complexes in membrane traffic: convergence through a common Rab. Nature reviews. Molecular cell biology 11, 759-763.

Bauer, N.M., Moos, C., van Horssen, J., Witte, M., van der Valk, P., Altenhein, B., Luhmann, H.J., White, R., 2012. Myelin basic protein synthesis is regulated by small non-coding RNA 715. EMBO reports $13,827-834$.

Bauman, M.L., Kemper, T.L., Arin, D.M., 1995. Microscopic observations of the brain in Rett syndrome. Neuropediatrics 26, 105-108.

Bem, D., Yoshimura, S., Nunes-Bastos, R., Bond, F.C., Kurian, M.A., Rahman, F., Handley, M.T., Hadzhiev, Y., Masood, I., Straatman-Iwanowska, A.A., Cullinane, A.R., McNeill, A., Pasha, S.S., Kirby, G.A., Foster, K., Ahmed, Z., Morton, J.E., Williams, D., Graham, J.M., Dobyns, W.B., Burglen, L., Ainsworth, J.R., Gissen, P., Muller, F., Maher, E.R., Barr, F.A., Aligianis, I.A., 2011. Loss-of-function mutations in RAB18 cause Warburg micro syndrome. Am J Hum Genet 88, 499-507.

Ben-Zeev, B., Hoffman, C., Lev, D., Watemberg, N., Malinger, G., Brand, N., Lerman-Sagie, T., 2003. Progressive cerebellocerebral atrophy: a new syndrome with microcephaly, mental retardation, and spastic quadriplegia. J Med Genet 40, e96.

Bercury, K.K., Macklin, W.B., 2015. Dynamics and mechanisms of CNS myelination. Dev Cell 32, 447-458.

Bergo, A., Strollo, M., Gai, M., Barbiero, I., Stefanelli, G., Sertic, S., Cobolli Gigli, C., Di Cunto, F., Kilstrup-Nielsen, C., Landsberger, N., 2015. Methyl-CpG binding protein 2 (MeCP2) localizes at the centrosome and is required for proper mitotic spindle organization. J Biol Chem 290, 3223-3237.

Binotti, B., Pavlos, N.J., Riedel, D., Wenzel, D., Vorbruggen, G., Schalk, A.M., Kuhnel, K., Boyken, J., Erck, C., Martens, H., Chua, J.J., Jahn, R., 2015. The GTPase Rab26 links synaptic vesicles to the autophagy pathway. eLife 4, e05597.

Bockaert, J., Marin, P., 2015. mTOR in Brain Physiology and Pathologies. Physiological reviews 95, 1157-1187.

Boncompain, G., Perez, F., 2013a. Fluorescence-based analysis of trafficking in mammalian cells. Methods in cell biology 118, 179-194.

Boncompain, G., Perez, F., 2013b. The many routes of Golgi-dependent trafficking. Histochemistry and cell biology 140, 251-260. 
Bonifacino, J.S., Hierro, A., 2011. Transport according to GARP: receiving retrograde cargo at the trans-Golgi network. Trends in cell biology 21, 159-167.

Borck, G., Wunram, H., Steiert, A., Volk, A.E., Korber, F., Roters, S., Herkenrath, P., Wollnik, B., Morris-Rosendahl, D.J., Kubisch, C., 2011. A homozygous RAB3GAP2 mutation causes Warburg Micro syndrome. Hum Genet 129, 45-50.

Bradke, F., Dotti, C.G., 1997. Neuronal polarity: vectorial cytoplasmic flow precedes axon formation. Neuron 19, 1175-1186.

Brugger, B., Sandhoff, R., Wegehingel, S., Gorgas, K., Malsam, J., Helms, J.B., Lehmann, W.D., Nickel, W., Wieland, F.T., 2000. Evidence for segregation of sphingomyelin and cholesterol during formation of COPI-coated vesicles. The Journal of cell biology 151, 507-518.

Bultema, J.J., Di Pietro, S.M., 2013. Cell type-specific Rab32 and Rab38 cooperate with the ubiquitous lysosome biogenesis machinery to synthesize specialized lysosome-related organelles. Small GTPases 4, 16-21.

Burgo, A., Sotirakis, E., Simmler, M.C., Verraes, A., Chamot, C., Simpson, J.C., Lanzetti, L., Proux-Gillardeaux, V., Galli, T., 2009. Role of Varp, a Rab21 exchange factor and TIVAMP/VAMP7 partner, in neurite growth. EMBO reports 10, 1117-1124.

Caceres, A., Paglini G., Quiroga S., Ferreira A., 2007. Role of the Golgi Apparatus During Axon Formation. Intracellular Mechanisms for Neuritogenesis, 136-154.

Carson, J.H., Worboys, K., Ainger, K., Barbarese, E., 1997. Translocation of myelin basic protein mRNA in oligodendrocytes requires microtubules and kinesin. Cell motility and the cytoskeleton 38, 318-328.

Chabin-Brion, K., Marceiller, J., Perez, F., Settegrana, C., Drechou, A., Durand, G., Pous, C., 2001. The Golgi complex is a microtubule-organizing organelle. Mol Biol Cell 12, 2047-2060.

Chen, L., Hu, J., Yun, Y., Wang, T., 2010. Rab36 regulates the spatial distribution of late endosomes and lysosomes through a similar mechanism to Rab34. Molecular membrane biology 27, 23-30.

Chen, T., Han, Y., Yang, M., Zhang, W., Li, N., Wan, T., Guo, J., Cao, X., 2003. Rab39, a novel Golgi-associated Rab GTPase from human dendritic cells involved in cellular endocytosis. Biochemical and biophysical research communications 303, 1114-1120.

Cheng, C.Y., Wu, J.C., Tsai, J.W., Nian, F.S., Wu, P.C., Kao, L.S., Fann, M.J., Tsai, S.J., Liou, Y.J., Tai, C.Y., Hong, C.J., 2015. ENU mutagenesis identifies mice modeling Warburg Micro Syndrome with sensory axon degeneration caused by a deletion in Rab18. Exp Neurol 267, 143-151.

Cheng, E., Trombetta, S.E., Kovacs, D., Beech, R.D., Ariyan, S., Reyes-Mugica, M., McNiff, J.M., Narayan, D., Kluger, H.M., Picardo, M., Halaban, R., 2006. Rab33A: characterization, expression, and suppression by epigenetic modification. The Journal of investigative dermatology 126, 2257-2271.

Climer, L.K., Dobretsov, M., Lupashin, V., 2015. Defects in the COG complex and COGrelated trafficking regulators affect neuronal Golgi function. Frontiers in neuroscience $9,405$.

Cohn, D.H., Ehtesham, N., Krakow, D., Unger, S., Shanske, A., Reinker, K., Powell, B.R., Rimoin, D.L., 2003. Mental retardation and abnormal skeletal development (DyggveMelchior-Clausen dysplasia) due to mutations in a novel, evolutionarily conserved gene. Am J Hum Genet 72, 419-428.

Colman, D.R., Kreibich, G., Frey, A.B., Sabatini, D.D., 1982. Synthesis and incorporation of myelin polypeptides into CNS myelin. The Journal of cell biology 95, 598-608.

Cooper, A.A., Gitler, A.D., Cashikar, A., Haynes, C.M., Hill, K.J., Bhullar, B., Liu, K., Xu, K., Strathearn, K.E., Liu, F., Cao, S., Caldwell, K.A., Caldwell, G.A., Marsischky, G., Kolodner, R.D., Labaer, J., Rochet, J.C., Bonini, N.M., Lindquist, S., 2006. Alpha- 
synuclein blocks ER-Golgi traffic and Rab1 rescues neuron loss in Parkinson's models. Science 313, 324-328.

Corbier, C., Sellier, C., 2016. C9ORF72 is a GDP/GTP exchange factor for Rab8 and Rab39 and regulates autophagy. Small GTPases, 0.

Cox, J.V., Kansal, R., Whitt, M.A., 2016. Rab43 regulates the sorting of a subset of membrane protein cargo through the medial Golgi. Mol Biol Cell 27, 1834-1844.

Cronk, J.C., Derecki, N.C., Litvak, V., Kipnis, J., 2016. Unexpected cellular players in Rett syndrome pathology. Neurobiology of disease 92, 64-71.

de Anda, F.C., Pollarolo, G., Da Silva, J.S., Camoletto, P.G., Feiguin, F., Dotti, C.G., 2005. Centrosome localization determines neuronal polarity. Nature 436, 704-708.

De Matteis, M.A., Luini, A., 2008. Exiting the Golgi complex. Nature reviews. Molecular cell biology 9, 273-284.

Dejgaard, S.Y., Murshid, A., Erman, A., Kizilay, O., Verbich, D., Lodge, R., Dejgaard, K., LyHartig, T.B., Pepperkok, R., Simpson, J.C., Presley, J.F., 2008. Rab18 and Rab43 have key roles in ER-Golgi trafficking. J Cell Sci 121, 2768-2781.

Delepine, C., Nectoux, J., Bahi-Buisson, N., Chelly, J., Bienvenu, T., 2013. MeCP2 deficiency is associated with impaired microtubule stability. FEBS Lett 587, 245-253.

Diao, A., Rahman, D., Pappin, D.J., Lucocq, J., Lowe, M., 2003. The coiled-coil membrane protein golgin-84 is a novel rab effector required for Golgi ribbon formation. The Journal of cell biology 160, 201-212.

Dimitrov, A., Paupe, V., Gueudry, C., Sibarita, J.B., Raposo, G., Vielemeyer, O., Gilbert, T., Csaba, Z., Attie-Bitach, T., Cormier-Daire, V., Gressens, P., Rustin, P., Perez, F., El Ghouzzi, V., 2009. The gene responsible for Dyggve-Melchior-Clausen syndrome encodes a novel peripheral membrane protein dynamically associated with the Golgi apparatus. Hum Mol Genet 18, 440-453.

Distel, M., Hocking, J.C., Volkmann, K., Koster, R.W., 2010. The centrosome neither persistently leads migration nor determines the site of axonogenesis in migrating neurons in vivo. The Journal of cell biology 191, 875-890.

Dixon, J.S., 1967. "Phagocytic" lysosomes in chromatolytic neurones. Nature 215, 657-658.

Donnelly, C.J., Fainzilber, M., Twiss, J.L., 2010. Subcellular communication through RNA transport and localized protein synthesis. Traffic 11, 1498-1505.

Duncan, J.E., Goldstein, L.S., 2006. The genetics of axonal transport and axonal transport disorders. PLoS Genet 2, e124.

Dupuis, N., Fafouri, A., Bayot, A., Kumar, M., Lecharpentier, T., Ball, G., Edwards, D., Bernard, V., Dournaud, P., Drunat, S., Vermelle-Andrzejewski, M., Vilain, C., Abramowicz, M., Desir, J., Bonaventure, J., Gareil, N., Boncompain, G., Csaba, Z., Perez, F., Passemard, S., Gressens, P., El Ghouzzi, V., 2015. Dymeclin deficiency causes postnatal microcephaly, hypomyelination and reticulum-to-Golgi trafficking defects in mice and humans. Hum Mol Genet 24, 2771-2783.

Dupuis, N., Lebon, S., Kumar, M., Drunat, S., Graul-Neumann, L.M., Gressens, P., El Ghouzzi, V., 2013. A Novel RAB33B Mutation in Smith-McCort Dysplasia. Hum Mutat 34, 283-286.

Dutta, D., Donaldson, J.G., 2015. Rab and Arf G proteins in endosomal trafficking. Methods in cell biology 130, 127-138.

Ebrahimi-Fakhari, D., Saffari, A., Wahlster, L., Lu, J., Byrne, S., Hoffmann, G.F., Jungbluth, H., Sahin, M., 2016. Congenital disorders of autophagy: an emerging novel class of inborn errors of neuro-metabolism. Brain 139, 317-337.

El Ghouzzi, V., Dagoneau, N., Kinning, E., Thauvin-Robinet, C., Chemaitilly, W., ProstSquarcioni, C., Al-Gazali, L.I., Verloes, A., Le Merrer, M., Munnich, A., Trembath, R.C., Cormier-Daire, V., 2003. Mutations in a novel gene Dymeclin (FLJ20071) are responsible for Dyggve-Melchior-Clausen syndrome. Hum Mol Genet 12, 357-364. 
Falk, M.J., Feiler, H.S., Neilson, D.E., Maxwell, K., Lee, J.V., Segall, S.K., Robin, N.H., Wilhelmsen, K.C., Traskelin, A.L., Kolehmainen, J., Lehesjoki, A.E., Wiznitzer, M., Warman, M.L., 2004. Cohen syndrome in the Ohio Amish. Am J Med Genet A 128A, 23-28.

Feinstein, M., Flusser, H., Lerman-Sagie, T., Ben-Zeev, B., Lev, D., Agamy, O., Cohen, I., Kadir, R., Sivan, S., Leshinsky-Silver, E., Markus, B., Birk, O.S., 2014. VPS53 mutations cause progressive cerebello-cerebral atrophy type 2 (PCCA2). J Med Genet 51, 303-308.

Feng, Y., He, D., Yao, Z., Klionsky, D.J., 2014. The machinery of macroautophagy. Cell research 24, 24-41.

Fernandez-Fernandez, M.R., Ruiz-Garcia, D., Martin-Solana, E., Chichon, F.J., Carrascosa, J.L., Fernandez, J.J., 2017. 3D electron tomography of brain tissue unveils distinct Golgi structures that sequester cytoplasmic contents in neurons. J Cell Sci 130, 83-89.

Fields, R.D., 2010. Neuroscience. Change in the brain's white matter. Science 330, 768-769.

Foulquier, F., Ungar, D., Reynders, E., Zeevaert, R., Mills, P., Garcia-Silva, M.T., Briones, P., Winchester, B., Morelle, W., Krieger, M., Annaert, W., Matthijs, G., 2007. A new inborn error of glycosylation due to a $\operatorname{Cog} 8$ deficiency reveals a critical role for the Cog1-Cog8 interaction in COG complex formation. Hum Mol Genet 16, 717-730.

Foulquier, F., Vasile, E., Schollen, E., Callewaert, N., Raemaekers, T., Quelhas, D., Jaeken, J., Mills, P., Winchester, B., Krieger, M., Annaert, W., Matthijs, G., 2006. Conserved oligomeric Golgi complex subunit 1 deficiency reveals a previously uncharacterized congenital disorder of glycosylation type II. Proc Natl Acad Sci U S A 103, 3764-3769.

Franker, M.A., Hoogenraad, C.C., 2013. Microtubule-based transport - basic mechanisms, traffic rules and role in neurological pathogenesis. J Cell Sci 126, 2319-2329.

Freeze, H.H., Ng, B.G., 2011. Golgi glycosylation and human inherited diseases. Cold Spring Harbor perspectives in biology 3, a005371.

Fukazawa, N., Ayukawa, K., Nishikawa, K., Ohashi, H., Ichihara, N., Hikawa, Y., Abe, T., Kudo, Y., Kiyama, H., Wada, K., Aoki, S., 2006. Identification and functional characterization of mouse TPO1 as a myelin membrane protein. Brain Res 1070, 1-14.

Fukuda, M., 2013. Rab27 effectors, pleiotropic regulators in secretory pathways. Traffic 14, 949-963.

Fukui, K., Sasaki, T., Imazumi, K., Matsuura, Y., Nakanishi, H., Takai, Y., 1997. Isolation and characterization of a GTPase activating protein specific for the Rab3 subfamily of small G proteins. J Biol Chem 272, 4655-4658.

Gardiol, A., Racca, C., Triller, A., 1999. Dendritic and postsynaptic protein synthetic machinery. J Neurosci 19, 168-179.

Ge, L., Wilz, L., Schekman, R., 2015. Biogenesis of autophagosomal precursors for LC3 lipidation from the ER-Golgi intermediate compartment. Autophagy 11, 2372-2374.

Geng, J., Nair, U., Yasumura-Yorimitsu, K., Klionsky, D.J., 2010. Post-Golgi Sec proteins are required for autophagy in Saccharomyces cerevisiae. Mol Biol Cell 21, 2257-2269.

Gerondopoulos, A., Bastos, R.N., Yoshimura, S., Anderson, R., Carpanini, S., Aligianis, I., Handley, M.T., Barr, F.A., 2014. Rab18 and a Rab18 GEF complex are required for normal ER structure. The Journal of cell biology 205, 707-720.

Giannandrea, M., Bianchi, V., Mignogna, M.L., Sirri, A., Carrabino, S., D'Elia, E., Vecellio, M., Russo, S., Cogliati, F., Larizza, L., Ropers, H.H., Tzschach, A., Kalscheuer, V., Oehl-Jaschkowitz, B., Skinner, C., Schwartz, C.E., Gecz, J., Van Esch, H., Raynaud, M., Chelly, J., de Brouwer, A.P., Toniolo, D., D'Adamo, P., 2010. Mutations in the small GTPase gene RAB39B are responsible for X-linked mental retardation associated with autism, epilepsy, and macrocephaly. Am J Hum Genet 86, 185-195.

Gielen, E., Baron, W., Vandeven, M., Steels, P., Hoekstra, D., Ameloot, M., 2006. Rafts in oligodendrocytes: evidence and structure-function relationship. Glia 54, 499-512. 
Gillingham, A.K., Sinka, R., Torres, I.L., Lilley, K.S., Munro, S., 2014. Toward a comprehensive map of the effectors of rab GTPases. Dev Cell 31, 358-373.

Goldenberg, N.M., Grinstein, S., Silverman, M., 2007. Golgi-bound Rab34 is a novel member of the secretory pathway. Mol Biol Cell 18, 4762-4771.

Gonatas, N.K., Stieber, A., Gonatas, J.O., 2006. Fragmentation of the Golgi apparatus in neurodegenerative diseases and cell death. Journal of the neurological sciences 246, 21 30.

Gonzalez, C., Canovas, J., Fresno, J., Couve, E., Court, F.A., Couve, A., 2016. Axons provide the secretory machinery for trafficking of voltage-gated sodium channels in peripheral nerve. Proc Natl Acad Sci U S A 113, 1823-1828.

Goud, B., Gleeson, P.A., 2010. TGN golgins, Rabs and cytoskeleton: regulating the Golgi trafficking highways. Trends in cell biology 20, 329-336.

Goud, B.A.A., 2012. Rab6 GTPase. Rab GTPases and Membrane Trafficking 13, 34-46.

Grigoriev, I., Splinter, D., Keijzer, N., Wulf, P.S., Demmers, J., Ohtsuka, T., Modesti, M., Maly, I.V., Grosveld, F., Hoogenraad, C.C., Akhmanova, A., 2007. Rab6 regulates transport and targeting of exocytotic carriers. Dev Cell 13, 305-314.

Grigoriev, I., Yu, K.L., Martinez-Sanchez, E., Serra-Marques, A., Smal, I., Meijering, E., Demmers, J., Peranen, J., Pasterkamp, R.J., van der Sluijs, P., Hoogenraad, C.C., Akhmanova, A., 2011. Rab6, Rab8, and MICAL3 cooperate in controlling docking and fusion of exocytotic carriers. Curr Biol 21, 967-974.

Gronemeyer, T., Wiese, S., Grinhagens, S., Schollenberger, L., Satyagraha, A., Huber, L.A., Meyer, H.E., Warscheid, B., Just, W.W., 2013. Localization of Rab proteins to peroxisomes: a proteomics and immunofluorescence study. FEBS Lett 587, 328-338.

Guerra, F., Bucci, C., 2016. Multiple Roles of the Small GTPase Rab7. Cells 5.

Guo, Y., Chang, C., Huang, R., Liu, B., Bao, L., Liu, W., 2012. AP1 is essential for generation of autophagosomes from the trans-Golgi network. J Cell Sci 125, 1706-1715.

Guo, Y., Sirkis, D.W., Schekman, R., 2014. Protein sorting at the trans-Golgi network. Annual review of cell and developmental biology 30, 169-206.

Haas, A.K., Yoshimura, S., Stephens, D.J., Preisinger, C., Fuchs, E., Barr, F.A., 2007. Analysis of GTPase-activating proteins: Rab1 and Rab43 are key Rabs required to maintain a functional Golgi complex in human cells. J Cell Sci 120, 2997-3010.

Haase, G., Rabouille, C., 2015. Golgi Fragmentation in ALS Motor Neurons. New Mechanisms Targeting Microtubules, Tethers, and Transport Vesicles. Frontiers in neuroscience 9, 448.

Handley, M.T., Carpanini, S.M., Mali, G.R., Sidjanin, D.J., Aligianis, I.A., Jackson, I.J., FitzPatrick, D.R., 2015. Warburg Micro syndrome is caused by RAB18 deficiency or dysregulation. Open biology 5, 150047.

Handley, M.T., Morris-Rosendahl, D.J., Brown, S., Macdonald, F., Hardy, C., Bem, D., Carpanini, S.M., Borck, G., Martorell, L., Izzi, C., Faravelli, F., Accorsi, P., Pinelli, L., Basel-Vanagaite, L., Peretz, G., Abdel-Salam, G.M., Zaki, M.S., Jansen, A., Mowat, D., Glass, I., Stewart, H., Mancini, G., Lederer, D., Roscioli, T., Giuliano, F., Plomp, A.S., Rolfs, A., Graham, J.M., Seemanova, E., Poo, P., Garcia-Cazorla, A., Edery, P., Jackson, I.J., Maher, E.R., Aligianis, I.A., 2013. Mutation spectrum in RAB3GAP1, RAB3GAP2, and RAB18 and genotype-phenotype correlations in warburg micro syndrome and Martsolf syndrome. Hum Mutat 34, 686-696.

Hara, T., Nakamura, K., Matsui, M., Yamamoto, A., Nakahara, Y., Suzuki-Migishima, R., Yokoyama, M., Mishima, K., Saito, I., Okano, H., Mizushima, N., 2006. Suppression of basal autophagy in neural cells causes neurodegenerative disease in mice. Nature 441, 885-889.

He, C., Levine, B., 2010. The Beclin 1 interactome. Curr Opin Cell Biol 22, 140-149.

He, S., Ni, D., Ma, B., Lee, J.H., Zhang, T., Ghozalli, I., Pirooz, S.D., Zhao, Z., Bharatham, N., Li, B., Oh, S., Lee, W.H., Takahashi, Y., Wang, H.G., Minassian, A., Feng, P., Deretic, 
V., Pepperkok, R., Tagaya, M., Yoon, H.S., Liang, C., 2013. PtdIns(3)P-bound UVRAG coordinates Golgi-ER retrograde and Atg9 transport by differential interactions with the ER tether and the beclin 1 complex. Nat Cell Biol 15, 1206-1219.

Heffernan, L.F., Simpson, J.C., 2014. The trials and tubule-ations of Rab6 involvement in Golgi-to-ER retrograde transport. Biochemical Society transactions 42, 1453-1459.

Heimer, G., Oz-Levi, D., Eyal, E., Edvardson, S., Nissenkorn, A., Ruzzo, E.K., Szeinberg, A., Maayan, C., Mai-Zahav, M., Efrati, O., Pras, E., Reznik-Wolf, H., Lancet, D., Goldstein, D.B., Anikster, Y., Shalev, S.A., Elpeleg, O., Ben Zeev, B., 2016. TECPR2 mutations cause a new subtype of familial dysautonomia like hereditary sensory autonomic neuropathy with intellectual disability. European journal of paediatric neurology : EJPN : official journal of the European Paediatric Neurology Society 20, 69-79.

Hernandez, D., Torres, C.A., Setlik, W., Cebrian, C., Mosharov, E.V., Tang, G., Cheng, H.C., Kholodilov, N., Yarygina, O., Burke, R.E., Gershon, M., Sulzer, D., 2012. Regulation of presynaptic neurotransmission by macroautophagy. Neuron 74, 277-284.

Hirokawa, N., Takemura, R., 2005. Molecular motors and mechanisms of directional transport in neurons. Nat Rev Neurosci 6, 201-214.

Holt, C.E., Bullock, S.L., 2009. Subcellular mRNA localization in animal cells and why it matters. Science 326, 1212-1216.

Holtzman, E., Novikoff, A.B., 1965. Lysomes in the rat sciatic nerve following crush. The Journal of cell biology 27, 651-669.

Homma, Y., Fukuda, M., 2016. Rabin8 regulates neurite outgrowth in both GEF activitydependent and -independent manners. Mol Biol Cell 27, 2107-2118.

Horton, A.C., Ehlers, M.D., 2003. Neuronal polarity and trafficking. Neuron 40, 277-295.

Horton, A.C., Racz, B., Monson, E.E., Lin, A.L., Weinberg, R.J., Ehlers, M.D., 2005. Polarized secretory trafficking directs cargo for asymmetric dendrite growth and morphogenesis. Neuron 48, 757-771.

Hu, Z., Yang, B., Mo, X., Xiao, H., 2015. Mechanism and Regulation of Autophagy and Its Role in Neuronal Diseases. Molecular neurobiology 52, 1190-1209.

Huang, W., She, L., Chang, X.Y., Yang, R.R., Wang, L., Ji, H.B., Jiao, J.W., Poo, M.M., 2014. Protein kinase LKB1 regulates polarized dendrite formation of adult hippocampal newborn neurons. Proc Natl Acad Sci U S A 111, 469-474.

Itoh, T., Fujita, N., Kanno, E., Yamamoto, A., Yoshimori, T., Fukuda, M., 2008. Golgi-resident small GTPase Rab33B interacts with Atg16L and modulates autophagosome formation. Mol Biol Cell 19, 2916-2925.

Jain, N., Ganesh, S., 2016. Emerging nexus between RAB GTPases, autophagy and neurodegeneration. Autophagy 12, 900-904.

Jang, S.Y., Shin, Y.K., Park, S.Y., Park, J.Y., Rha, S.H., Kim, J.K., Lee, H.J., Park, H.T., 2015. Autophagy is involved in the reduction of myelinating Schwann cell cytoplasm during myelin maturation of the peripheral nerve. PLoS One 10, e 0116624.

Jareb, M., Banker, G., 1997. Inhibition of axonal growth by brefeldin A in hippocampal neurons in culture. J Neurosci 17, 8955-8963.

Jean, S., Cox, S., Nassari, S., Kiger, A.A., 2015. Starvation-induced MTMR13 and RAB21 activity regulates VAMP8 to promote autophagosome-lysosome fusion. EMBO reports 16, 297-311.

Jeyifous, O., Waites, C.L., Specht, C.G., Fujisawa, S., Schubert, M., Lin, E.I., Marshall, J., Aoki, C., de Silva, T., Montgomery, J.M., Garner, C.C., Green, W.N., 2009. SAP97 and CASK mediate sorting of NMDA receptors through a previously unknown secretory pathway. Nat Neurosci 12, 1011-1019.

Jin, R.U., Mills, J.C., 2014. RAB26 coordinates lysosome traffic and mitochondrial localization. J Cell Sci 127, 1018-1032. 
Joachim, J., Jefferies, H.B., Razi, M., Frith, D., Snijders, A.P., Chakravarty, P., Judith, D., Tooze, S.A., 2015. Activation of ULK Kinase and Autophagy by GABARAP Trafficking from the Centrosome Is Regulated by WAC and GM130. Molecular cell 60, 899-913.

Joshi, G., Bekier, M.E., 2nd, Wang, Y., 2015. Golgi fragmentation in Alzheimer's disease. Frontiers in neuroscience 9, 340.

Jung, H., Yoon, B.C., Holt, C.E., 2012. Axonal mRNA localization and local protein synthesis in nervous system assembly, maintenance and repair. Nat Rev Neurosci 13, 308-324.

Junutula, J.R., De Maziere, A.M., Peden, A.A., Ervin, K.E., Advani, R.J., van Dijk, S.M., Klumperman, J., Scheller, R.H., 2004. Rab14 is involved in membrane trafficking between the Golgi complex and endosomes. Mol Biol Cell 15, 2218-2229.

Kadir, R., Harel, T., Markus, B., Perez, Y., Bakhrat, A., Cohen, I., Volodarsky, M., FeintseinLinial, M., Chervinski, E., Zlotogora, J., Sivan, S., Birnbaum, R.Y., Abdu, U., Shalev, S., Birk, O.S., 2016. ALFY-Controlled DVL3 Autophagy Regulates Wnt Signaling, Determining Human Brain Size. PLoS Genet 12, e1005919.

Kakar, N., Goebel, I., Daud, S., Nurnberg, G., Agha, N., Ahmad, A., Nurnberg, P., Kubisch, C., Ahmad, J., Borck, G., 2012. A homozygous splice site mutation in TRAPPC9 causes intellectual disability and microcephaly. Eur J Med Genet 55, 727-731.

Kapitein, L.C., Schlager, M.A., Kuijpers, M., Wulf, P.S., van Spronsen, M., MacKintosh, F.C., Hoogenraad, C.C., 2010. Mixed microtubules steer dynein-driven cargo transport into dendrites. Curr Biol 20, 290-299.

Kasmapour, B., Gronow, A., Bleck, C.K., Hong, W., Gutierrez, M.G., 2012. Size-dependent mechanism of cargo sorting during lysosome-phagosome fusion is controlled by Rab34. Proc Natl Acad Sci U S A 109, 20485-20490.

Kelly, E.E., Giordano, F., Horgan, C.P., Jollivet, F., Raposo, G., McCaffrey, M.W., 2012. Rab30 is required for the morphological integrity of the Golgi apparatus. Biology of the cell / under the auspices of the European Cell Biology Organization 104, 84-101.

Kim, H.J., Cho, M.H., Shim, W.H., Kim, J.K., Jeon, E.Y., Kim, D.H., Yoon, S.Y., 2016. Deficient autophagy in microglia impairs synaptic pruning and causes social behavioral defects. Molecular psychiatry.

Kivitie-Kallio, S., Autti, T., Salonen, O., Norio, R., 1998. MRI of the brain in the Cohen syndrome: a relatively large corpus callosum in patients with mental retardation and microcephaly. Neuropediatrics 29, 298-301.

Klemm, R.W., Ejsing, C.S., Surma, M.A., Kaiser, H.J., Gerl, M.J., Sampaio, J.L., de Robillard, Q., Ferguson, C., Proszynski, T.J., Shevchenko, A., Simons, K., 2009. Segregation of sphingolipids and sterols during formation of secretory vesicles at the trans-Golgi network. The Journal of cell biology 185, 601-612.

Klinkert, K., Echard, A., 2016. Rab35 GTPase: A Central Regulator of Phosphoinositides and F-actin in Endocytic Recycling and Beyond. Traffic 17, 1063-1077.

Kobayashi, H., Etoh, K., Ohbayashi, N., Fukuda, M., 2014. Rab35 promotes the recruitment of Rab8, Rab13 and Rab36 to recycling endosomes through MICAL-L1 during neurite outgrowth. Biology open 3, 803-814.

Kodera, H., Ando, N., Yuasa, I., Wada, Y., Tsurusaki, Y., Nakashima, M., Miyake, N., Saitoh, S., Matsumoto, N., Saitsu, H., 2015. Mutations in COG2 encoding a subunit of the conserved oligomeric golgi complex cause a congenital disorder of glycosylation. Clinical genetics 87, 455-460.

Kogel, T., Rudolf, R., Hodneland, E., Copier, J., Regazzi, R., Tooze, S.A., Gerdes, H.H., 2013. Rab3D is critical for secretory granule maturation in PC12 cells. PLoS One 8, e57321.

Komatsu, M., Waguri, S., Chiba, T., Murata, S., Iwata, J., Tanida, I., Ueno, T., Koike, M., Uchiyama, Y., Kominami, E., Tanaka, K., 2006. Loss of autophagy in the central nervous system causes neurodegeneration in mice. Nature 441, 880-884. 
Koreishi, M., Gniadek, T.J., Yu, S., Masuda, J., Honjo, Y., Satoh, A., 2013. The golgin tether giantin regulates the secretory pathway by controlling stack organization within Golgi apparatus. PLoS One 8, e59821.

Kosturko, L.D., Maggipinto, M.J., Korza, G., Lee, J.W., Carson, J.H., Barbarese, E., 2006. Heterogeneous nuclear ribonucleoprotein (hnRNP) E1 binds to hnRNP A2 and inhibits translation of A2 response element mRNAs. Mol Biol Cell 17, 3521-3533.

Kramer, E.M., Schardt, A., Nave, K.A., 2001. Membrane traffic in myelinating oligodendrocytes. Microscopy research and technique 52, 656-671.

Kristensen, A.R., Gsponer, J., Foster, L.J., 2012. A high-throughput approach for measuring temporal changes in the interactome. Nature methods 9, 907-909.

Kucera, A., Bakke, O., Progida, C., 2016. The multiple roles of Rab9 in the endolysosomal system. Communicative \& integrative biology 9, e1204498.

Lamb, C.A., Yoshimori, T., Tooze, S.A., 2013. The autophagosome: origins unknown, biogenesis complex. Nature reviews. Molecular cell biology 14, 759-774.

Laufman, O., Freeze, H.H., Hong, W., Lev, S., 2013a. Deficiency of the Cog8 subunit in normal and CDG-derived cells impairs the assembly of the COG and Golgi SNARE complexes. Traffic 14, 1065-1077.

Laufman, O., Hong, W., Lev, S., 2011. The COG complex interacts directly with Syntaxin 6 and positively regulates endosome-to-TGN retrograde transport. The Journal of cell biology 194, 459-472.

Laufman, O., Hong, W., Lev, S., 2013b. The COG complex interacts with multiple Golgi SNAREs and enhances fusogenic assembly of SNARE complexes. J Cell Sci 126, 1506-1516.

Laufman, O., Kedan, A., Hong, W., Lev, S., 2009. Direct interaction between the COG complex and the SM protein, Sly1, is required for Golgi SNARE pairing. EMBO J 28, 2006-2017.

Lee, M.S., Jun, D.H., Hwang, C.I., Park, S.S., Kang, J.J., Park, H.S., Kim, J., Kim, J.H., Seo, J.S., Park, W.Y., 2006. Selection of neural differentiation-specific genes by comparing profiles of random differentiation. Stem Cells 24, 1946-1955.

Lee, R.H., Iioka, H., Ohashi, M., Iemura, S., Natsume, T., Kinoshita, N., 2007. XRab40 and $\mathrm{XCullin} 5$ form a ubiquitin ligase complex essential for the noncanonical Wnt pathway. EMBO J 26, 3592-3606.

Lekman, A.Y., Hagberg, B.A., Svennerholm, L.T., 1991. Membrane cerebral lipids in Rett syndrome. Pediatric neurology 7, 186-190.

Li, C., Fan, Y., Lan, T.H., Lambert, N.A., Wu, G., 2012. Rab26 modulates the cell surface transport of alpha2-adrenergic receptors from the Golgi. J Biol Chem 287, 4278442794.

Liang, C.C., Wang, C., Peng, X., Gan, B., Guan, J.L., 2010. Neural-specific deletion of FIP200 leads to cerebellar degeneration caused by increased neuronal death and axon degeneration. J Biol Chem 285, 3499-3509.

Liegel, R.P., Handley, M.T., Ronchetti, A., Brown, S., Langemeyer, L., Linford, A., Chang, B., Morris-Rosendahl, D.J., Carpanini, S., Posmyk, R., Harthill, V., Sheridan, E., AbdelSalam, G.M., Terhal, P.A., Faravelli, F., Accorsi, P., Giordano, L., Pinelli, L., Hartmann, B., Ebert, A.D., Barr, F.A., Aligianis, I.A., Sidjanin, D.J., 2013. Loss-offunction mutations in TBC1D20 cause cataracts and male infertility in blind sterile mice and Warburg micro syndrome in humans. Am J Hum Genet 93, 1001-1014.

Liewen, H., Meinhold-Heerlein, I., Oliveira, V., Schwarzenbacher, R., Luo, G., Wadle, A., Jung, M., Pfreundschuh, M., Stenner-Liewen, F., 2005. Characterization of the human GARP (Golgi associated retrograde protein) complex. Experimental cell research 306, 24-34.

Lingwood, D., Simons, K., 2010. Lipid rafts as a membrane-organizing principle. Science 327, 46-50. 
Liu, C., Mei, M., Li, Q., Roboti, P., Pang, Q., Ying, Z., Gao, F., Lowe, M., Bao, S., 2017. Loss of the golgin GM130 causes Golgi disruption, Purkinje neuron loss, and ataxia in mice. Proc Natl Acad Sci U S A 114, 346-351.

Liu, S., Hunt, L., Storrie, B., 2013. Rab41 is a novel regulator of Golgi apparatus organization that is needed for ER-to-Golgi trafficking and cell growth. PLoS One 8, e71886.

Liu, S., Storrie, B., 2012. Are Rab proteins the link between Golgi organization and membrane trafficking? Cell Mol Life Sci 69, 4093-4106.

Liyanage, V.R., Rastegar, M., 2014. Rett syndrome and MeCP2. Neuromolecular medicine 16, 231-264.

Longatti, A., Lamb, C.A., Razi, M., Yoshimura, S., Barr, F.A., Tooze, S.A., 2012. TBC1D14 regulates autophagosome formation via Rab11- and ULK1-positive recycling endosomes. The Journal of cell biology 197, 659-675.

Lowenstein, P.R., Morrison, E.E., Bain, D., Shering, A.F., Banting, G., Douglas, P., Castro, M.G., 1994. Polarized distribution of the trans-Golgi network marker TGN38 during the in vitro development of neocortical neurons: effects of nocodazole and brefeldin A. Eur J Neurosci 6, 1453-1465.

Lutcke, A., Parton, R.G., Murphy, C., Olkkonen, V.M., Dupree, P., Valencia, A., Simons, K., Zerial, M., 1994. Cloning and subcellular localization of novel rab proteins reveals polarized and cell type-specific expression. J Cell Sci 107 ( Pt 12), 3437-3448.

Machamer, C.E., 2015. The Golgi complex in stress and death. Frontiers in neuroscience 9, 421.

Maeder, C.I., Shen, K., Hoogenraad, C.C., 2014. Axon and dendritic trafficking. Curr Opin Neurobiol 27, 165-170.

Majeed, W., Liu, S., Storrie, B., 2014. Distinct sets of Rab6 effectors contribute to ZW10--and COG-dependent Golgi homeostasis. Traffic 15, 630-647.

Marangi, G., Leuzzi, V., Manti, F., Lattante, S., Orteschi, D., Pecile, V., Neri, G., Zollino, M., 2013. TRAPPC9-related autosomal recessive intellectual disability: report of a new mutation and clinical phenotype. Eur J Hum Genet 21, 229-232.

Marner, L., Nyengaard, J.R., Tang, Y., Pakkenberg, B., 2003. Marked loss of myelinated nerve fibers in the human brain with age. J Comp Neurol 462, 144-152.

Martin, S., Driessen, K., Nixon, S.J., Zerial, M., Parton, R.G., 2005. Regulated localization of Rab18 to lipid droplets: effects of lipolytic stimulation and inhibition of lipid droplet catabolism. J Biol Chem 280, 42325-42335.

Matejko, A.A., Ansari, D., 2015. Drawing connections between white matter and numerical and mathematical cognition: a literature review. Neuroscience and biobehavioral reviews $48,35-52$.

Matsui, T., Fukuda, M., 2011. Small GTPase Rab12 regulates transferrin receptor degradation: Implications for a novel membrane trafficking pathway from recycling endosomes to lysosomes. Cellular logistics 1, 155-158.

Matsui, T., Fukuda, M., 2013. Rab12 regulates mTORC1 activity and autophagy through controlling the degradation of amino-acid transporter PAT4. EMBO reports 14,450 457.

Merianda, T.T., Lin, A.C., Lam, J.S., Vuppalanchi, D., Willis, D.E., Karin, N., Holt, C.E., Twiss, J.L., 2009. A functional equivalent of endoplasmic reticulum and Golgi in axons for secretion of locally synthesized proteins. Mol Cell Neurosci 40, 128-142.

Mikhaylova, M., Bera, S., Kobler, O., Frischknecht, R., Kreutz, M.R., 2016. A Dendritic Golgi Satellite between ERGIC and Retromer. Cell reports 14, 189-199.

Militello, R.D., Munafo, D.B., Beron, W., Lopez, L.A., Monier, S., Goud, B., Colombo, M.I., 2013. Rab24 is required for normal cell division. Traffic 14, 502-518.

Miller, P.M., Folkmann, A.W., Maia, A.R., Efimova, N., Efimov, A., Kaverina, I., 2009. Golgiderived CLASP-dependent microtubules control Golgi organization and polarized trafficking in motile cells. Nat Cell Biol 11, 1069-1080. 
Miller, V.J., Sharma, P., Kudlyk, T.A., Frost, L., Rofe, A.P., Watson, I.J., Duden, R., Lowe, M., Lupashin, V.V., Ungar, D., 2013. Molecular insights into vesicle tethering at the Golgi by the conserved oligomeric Golgi (COG) complex and the golgin TATA element modulatory factor (TMF). $J$ Biol Chem 288, 4229-4240.

Mir, A., Kaufman, L., Noor, A., Motazacker, M.M., Jamil, T., Azam, M., Kahrizi, K., Rafiq, M.A., Weksberg, R., Nasr, T., Naeem, F., Tzschach, A., Kuss, A.W., Ishak, G.E., Doherty, D., Ropers, H.H., Barkovich, A.J., Najmabadi, H., Ayub, M., Vincent, J.B., 2009. Identification of mutations in TRAPPC9, which encodes the NIK- and IKK-betabinding protein, in nonsyndromic autosomal-recessive mental retardation. Am J Hum Genet 85, 909-915.

Miserey-Lenkei, S., Chalancon, G., Bardin, S., Formstecher, E., Goud, B., Echard, A., 2010. $\mathrm{Rab}$ and actomyosin-dependent fission of transport vesicles at the Golgi complex. Nat Cell Biol 12, 645-654.

Miyake, K., Nagai, K., 2007. Phosphorylation of methyl-CpG binding protein 2 (MeCP2) regulates the intracellular localization during neuronal cell differentiation. Neurochemistry international 50, 264-270.

Mizushima, N., Komatsu, M., 2011. Autophagy: renovation of cells and tissues. Cell 147, 728741.

Mochida, G.H., Mahajnah, M., Hill, A.D., Basel-Vanagaite, L., Gleason, D., Hill, R.S., Bodell, A., Crosier, M., Straussberg, R., Walsh, C.A., 2009. A truncating mutation of TRAPPC9 is associated with autosomal-recessive intellectual disability and postnatal microcephaly. Am J Hum Genet 85, 897-902.

Morava, E., Zeevaert, R., Korsch, E., Huijben, K., Wopereis, S., Matthijs, G., Keymolen, K., Lefeber, D.J., De Meirleir, L., Wevers, R.A., 2007. A common mutation in the COG7 gene with a consistent phenotype including microcephaly, adducted thumbs, growth retardation, VSD and episodes of hyperthermia. Eur J Hum Genet 15, 638-645.

Mori, Y., Matsui, T., Omote, D., Fukuda, M., 2013. Small GTPase Rab39A interacts with UACA and regulates the retinoic acid-induced neurite morphology of Neuro2A cells. Biochemical and biophysical research communications 435, 113-119.

Moyer, B.D., Allan, B.B., Balch, W.E., 2001. Rab1 interaction with a GM130 effector complex regulates COPII vesicle cis--Golgi tethering. Traffic 2, 268-276.

Muller, C., Bauer, N.M., Schafer, I., White, R., 2013. Making myelin basic protein -from mRNA transport to localized translation. Frontiers in cellular neuroscience 7, 169.

Nagano, F., Sasaki, T., Fukui, K., Asakura, T., Imazumi, K., Takai, Y., 1998. Molecular cloning and characterization of the noncatalytic subunit of the Rab3 subfamily-specific GTPase-activating protein. J Biol Chem 273, 24781-24785.

Nakagomi, S., Barsoum, M.J., Bossy-Wetzel, E., Sutterlin, C., Malhotra, V., Lipton, S.A., 2008. A Golgi fragmentation pathway in neurodegeneration. Neurobiology of disease $29,221-231$.

Nakamura, N., 2010. Emerging new roles of GM130, a cis-Golgi matrix protein, in higher order cell functions. Journal of pharmacological sciences 112, 255-264.

Nakamura, N., Wei, J.H., Seemann, J., 2012. Modular organization of the mammalian Golgi apparatus. Curr Opin Cell Biol 24, 467-474.

Nakazawa, H., Sada, T., Toriyama, M., Tago, K., Sugiura, T., Fukuda, M., Inagaki, N., 2012. Rab33a mediates anterograde vesicular transport for membrane exocytosis and axon outgrowth. J Neurosci 32, 12712-12725.

Neefjes, J., van der Kant, R., 2014. Stuck in traffic: an emerging theme in diseases of the nervous system. Trends Neurosci 37, 66-76.

Nguyen, M.M., Stone, M.C., Rolls, M.M., 2011. Microtubules are organized independently of the centrosome in Drosophila neurons. Neural Dev 6, 38. 
Nishida, Y., Arakawa, S., Fujitani, K., Yamaguchi, H., Mizuta, T., Kanaseki, T., Komatsu, M., Otsu, K., Tsujimoto, Y., Shimizu, S., 2009. Discovery of Atg5/Atg7-independent alternative macroautophagy. Nature 461, 654-658.

Nishimura, N., Araki, K., Shinahara, W., Nakano, Y., Nishimura, K., Higashio, H., Sasaki, T., 2008. Interaction of Rab3B with microtubule-binding protein Gas8 in NIH 3T3 cells. Archives of biochemistry and biophysics 474, 136-142.

Nokes, R.L., Fields, I.C., Collins, R.N., Folsch, H., 2008. Rab13 regulates membrane trafficking between TGN and recycling endosomes in polarized epithelial cells. The Journal of cell biology 182, 845-853.

North, K.N., Fulton, A.B., Whiteman, D.A., 1995. Identical twins with Cohen syndrome. Am J Med Genet 58, 54-58.

O'Mahony, F., Wroblewski, K., O'Byrne, S.M., Jiang, H., Clerkin, K., Benhammou, J., Blaner, W.S., Beaven, S.W., 2015. Liver X receptors balance lipid stores in hepatic stellate cells through Rab18, a retinoid responsive lipid droplet protein. Hepatology 62, 615-626.

Oda, S., Nozawa, T., Nozawa-Minowa, A., Tanaka, M., Aikawa, C., Harada, H., Nakagawa, I., 2016. Golgi-Resident GTPase Rab30 Promotes the Biogenesis of Pathogen-Containing Autophagosomes. PLoS One 11, e0147061.

Okai, B., Lyall, N., Gow, N.A., Bain, J.M., Erwig, L.P., 2015. Rab14 regulates maturation of macrophage phagosomes containing the fungal pathogen Candida albicans and outcome of the host-pathogen interaction. Infection and immunity 83, 1523-1535.

Olkkonen, V.M., Dupree, P., Killisch, I., Lutcke, A., Zerial, M., Simons, K., 1993. Molecular cloning and subcellular localization of three GTP-binding proteins of the rab subfamily. J Cell Sci 106 ( Pt 4), 1249-1261.

Onnis, A., Finetti, F., Patrussi, L., Gottardo, M., Cassioli, C., Spano, S., Baldari, C.T., 2015. The small GTPase Rab29 is a common regulator of immune synapse assembly and ciliogenesis. Cell Death Differ 22, 1687-1699.

Opdam, F.J., Echard, A., Croes, H.J., van den Hurk, J.A., van de Vorstenbosch, R.A., Ginsel, L.A., Goud, B., Fransen, J.A., 2000. The small GTPase Rab6B, a novel Rab6 subfamily member, is cell-type specifically expressed and localised to the Golgi apparatus. $J$ Cell Sci 113 ( Pt 15), 2725-2735.

Orci, L., Ravazzola, M., Amherdt, M., Perrelet, A., Powell, S.K., Quinn, D.L., Moore, H.P., 1987. The trans-most cisternae of the Golgi complex: a compartment for sorting of secretory and plasma membrane proteins. Cell 51, 1039-1051.

Ori-McKenney, K.M., Jan, L.Y., Jan, Y.N., 2012. Golgi outposts shape dendrite morphology by functioning as sites of acentrosomal microtubule nucleation in neurons. Neuron 76, 921-930.

Osanai, K., Takahashi, K., Nakamura, K., Takahashi, M., Ishigaki, M., Sakuma, T., Toga, H., Suzuki, T., Voelker, D.R., 2005. Expression and characterization of Rab38, a new member of the Rab small G protein family. Biological chemistry 386, 143-153.

Osipovich, A.B., Jennings, J.L., Lin, Q., Link, A.J., Ruley, H.E., 2008. Dyggve-MelchiorClausen syndrome: chondrodysplasia resulting from defects in intracellular vesicle traffic. Proc Natl Acad Sci U S A 105, 16171-16176.

Oz-Levi, D., Ben-Zeev, B., Ruzzo, E.K., Hitomi, Y., Gelman, A., Pelak, K., Anikster, Y., Reznik-Wolf, H., Bar-Joseph, I., Olender, T., Alkelai, A., Weiss, M., Ben-Asher, E., Ge, D., Shianna, K.V., Elazar, Z., Goldstein, D.B., Pras, E., Lancet, D., 2012. Mutation in TECPR2 reveals a role for autophagy in hereditary spastic paraparesis. Am J Hum Genet 91, 1065-1072.

Ozeki, S., Cheng, J., Tauchi-Sato, K., Hatano, N., Taniguchi, H., Fujimoto, T., 2005. Rab18 localizes to lipid droplets and induces their close apposition to the endoplasmic reticulum-derived membrane. J Cell Sci 118, 2601-2611. 
Paladino, S., Sarnataro, D., Pillich, R., Tivodar, S., Nitsch, L., Zurzolo, C., 2004. Protein oligomerization modulates raft partitioning and apical sorting of GPI-anchored proteins. The Journal of cell biology 167, 699-709.

Papadimitriou, J.M., Hockey, A., Tan, N., Masters, C.L., 1988. Rett syndrome: abnormal membrane-bound lamellated inclusions in neurons and oligodendroglia. Am J Med Genet 29, 365-368.

Papanikou, E., Glick, B.S., 2014. Golgi compartmentation and identity. Curr Opin Cell Biol 29, 74-81.

Paupe, V., Gilbert, T., Le Merrer, M., Munnich, A., Cormier-Daire, V., El Ghouzzi, V., 2004. Recent advances in Dyggve-Melchior-Clausen syndrome. Mol Genet Metab 83, 51-59.

Peranen, J., 2011. Rab8 GTPase as a regulator of cell shape. Cytoskeleton 68, 527-539.

Philippe, O., Rio, M., Carioux, A., Plaza, J.M., Guigue, P., Molinari, F., Boddaert, N., BoleFeysot, C., Nitschke, P., Smahi, A., Munnich, A., Colleaux, L., 2009. Combination of linkage mapping and microarray-expression analysis identifies NF-kappaB signaling defect as a cause of autosomal-recessive mental retardation. Am J Hum Genet 85, 903908.

Pierce, J.P., Mayer, T., McCarthy, J.B., 2001. Evidence for a satellite secretory pathway in neuronal dendritic spines. Curr Biol 11, 351-355.

Plutner, H., Cox, A.D., Pind, S., Khosravi-Far, R., Bourne, J.R., Schwaninger, R., Der, C.J., Balch, W.E., 1991. Rab1b regulates vesicular transport between the endoplasmic reticulum and successive Golgi compartments. The Journal of cell biology 115, 31-43.

Pohodich, A.E., Zoghbi, H.Y., 2015. Rett syndrome: disruption of epigenetic control of postnatal neurological functions. Hum Mol Genet 24, R10-16.

Privat, A., Jacque, C., Bourre, J.M., Dupouey, P., Baumann, N., 1979. Absence of the major dense line in myelin of the mutant mouse "shiverer". Neuroscience letters 12, 107-112.

Pusapati, G.V., Luchetti, G., Pfeffer, S.R., 2012. Ric1-Rgp1 complex is a guanine nucleotide exchange factor for the late Golgi Rab6A GTPase and an effector of the medial Golgi Rab33B GTPase. J Biol Chem 287, 42129-42137.

Quassollo, G., Wojnacki, J., Salas, D.A., Gastaldi, L., Marzolo, M.P., Conde, C., Bisbal, M., Couve, A., Caceres, A., 2015. A RhoA Signaling Pathway Regulates Dendritic Golgi Outpost Formation. Curr Biol 25, 971-982.

Rabouille, C., Haase, G., 2015. Editorial: Golgi Pathology in Neurodegenerative Diseases. Frontiers in neuroscience 9, 489.

Ramirez, O.A., Couve, A., 2011. The endoplasmic reticulum and protein trafficking in dendrites and axons. Trends in cell biology 21, 219-227.

Rangaraju, S., Verrier, J.D., Madorsky, I., Nicks, J., Dunn, W.A., Jr., Notterpek, L., 2010. Rapamycin activates autophagy and improves myelination in explant cultures from neuropathic mice. $J$ Neurosci 30, 11388-11397.

Reggiori, F., Ungermann, C., 2017. Autophagosome Maturation and Fusion. Journal of molecular biology 429, 486-496.

Rodriguez-Gabin, A.G., Almazan, G., Larocca, J.N., 2004. Vesicle transport in oligodendrocytes: probable role of Rab40c protein. J Neurosci Res 76, 758-770.

Rodriguez-Gabin, A.G., Cammer, M., Almazan, G., Charron, M., Larocca, J.N., 2001. Role of rRAB22b, an oligodendrocyte protein, in regulation of transport of vesicles from trans Golgi to endocytic compartments. J Neurosci Res 66, 1149-1160.

Rosing, M., Ossendorf, E., Rak, A., Barnekow, A., 2007. Giantin interacts with both the small GTPase Rab6 and Rab1. Experimental cell research 313, 2318-2325.

Roux, J.C., Zala, D., Panayotis, N., Borges-Correia, A., Saudou, F., Villard, L., 2012. Modification of Mecp2 dosage alters axonal transport through the Huntingtin/Hap1 pathway. Neurobiology of disease 45, 786-795. 
Rydell, G.E., Renard, H.F., Garcia-Castillo, M.D., Dingli, F., Loew, D., Lamaze, C., Romer, W., Johannes, L., 2014. Rab12 localizes to Shiga toxin-induced plasma membrane invaginations and controls toxin transport. Traffic 15, 772-787.

Saraste, J., Lahtinen, U., Goud, B., 1995. Localization of the small GTP-binding protein rab1p to early compartments of the secretory pathway. J Cell Sci 108 ( Pt 4), 1541-1552.

Satoh, A., Wang, Y., Malsam, J., Beard, M.B., Warren, G., 2003. Golgin-84 is a rab1 binding partner involved in Golgi structure. Traffic 4, 153-161.

Schindler, C., Chen, Y., Pu, J., Guo, X., Bonifacino, J.S., 2015. EARP is a multisubunit tethering complex involved in endocytic recycling. Nat Cell Biol 17, 639-650.

Schlager, M.A., Hoogenraad, C.C., 2009. Basic mechanisms for recognition and transport of synaptic cargos. Molecular brain 2, 25.

Schlager, M.A., Kapitein, L.C., Grigoriev, I., Burzynski, G.M., Wulf, P.S., Keijzer, N., de Graaff, E., Fukuda, M., Shepherd, I.T., Akhmanova, A., Hoogenraad, C.C., 2010. Pericentrosomal targeting of Rab6 secretory vesicles by Bicaudal-D-related protein 1 (BICDR-1) regulates neuritogenesis. EMBO J 29, 1637-1651.

Schroter, S., Beckmann, S., Schmitt, H.D., 2016. ER arrival sites for COPI vesicles localize to hotspots of membrane trafficking. EMBO J 35, 1935-1955.

Schuck, S., Simons, K., 2004. Polarized sorting in epithelial cells: raft clustering and the biogenesis of the apical membrane. J Cell Sci 117, 5955-5964.

Schwarz, L., Goldbaum, O., Bergmann, M., Probst-Cousin, S., Richter-Landsberg, C., 2012. Involvement of macroautophagy in multiple system atrophy and protein aggregate formation in oligodendrocytes. Journal of molecular neuroscience : MN 47, 256-266.

Seifert, W., Kuhnisch, J., Maritzen, T., Horn, D., Haucke, V., Hennies, H.C., 2011. Cohen syndrome-associated protein, $\mathrm{COH} 1$, is a novel, giant Golgi matrix protein required for Golgi integrity. J Biol Chem 286, 37665-37675.

Seifert, W., Kuhnisch, J., Maritzen, T., Lommatzsch, S., Hennies, H.C., Bachmann, S., Horn, D., Haucke, V., 2015. Cohen syndrome-associated protein COH1 physically and functionally interacts with the small GTPase RAB6 at the Golgi complex and directs neurite outgrowth. J Biol Chem 290, 3349-3358.

Seltzer, L.E., Paciorkowski, A.R., 2014. Genetic disorders associated with postnatal microcephaly. American journal of medical genetics. Part C, Seminars in medical genetics 166C, 140-155.

Seto, S., Sugaya, K., Tsujimura, K., Nagata, T., Horii, T., Koide, Y., 2013. Rab39a interacts with phosphatidylinositol 3-kinase and negatively regulates autophagy induced by lipopolysaccharide stimulation in macrophages. PLoS One 8, e83324.

Shamseldin, H.E., Bennett, A.H., Alfadhel, M., Gupta, V., Alkuraya, F.S., 2016. GOLGA2, encoding a master regulator of golgi apparatus, is mutated in a patient with a neuromuscular disorder. Hum Genet 135, 245-251.

Shestakova, A., Suvorova, E., Pavliv, O., Khaidakova, G., Lupashin, V., 2007. Interaction of the conserved oligomeric Golgi complex with t-SNARE Syntaxin5a/Sed5 enhances intra-Golgi SNARE complex stability. The Journal of cell biology 179, 1179-1192.

Shestakova, A., Zolov, S., Lupashin, V., 2006. COG complex-mediated recycling of Golgi glycosyltransferases is essential for normal protein glycosylation. Traffic 7, 191-204.

Short, B., Preisinger, C., Korner, R., Kopajtich, R., Byron, O., Barr, F.A., 2001. A GRASP55rab2 effector complex linking Golgi structure to membrane traffic. The Journal of cell biology 155, 877-883.

Short, B., Preisinger, C., Schaletzky, J., Kopajtich, R., Barr, F.A., 2002. The Rab6 GTPase regulates recruitment of the dynactin complex to Golgi membranes. Curr Biol 12, 17921795.

Sidjanin, D.J., Park, A.K., Ronchetti, A., Martins, J., Jackson, W.T., 2016. TBC1D20 mediates autophagy as a key regulator of autophagosome maturation. Autophagy, 1-17. 
Simons, M., Kramer, E.M., Thiele, C., Stoffel, W., Trotter, J., 2000. Assembly of myelin by association of proteolipid protein with cholesterol- and galactosylceramide-rich membrane domains. The Journal of cell biology 151, 143-154.

Simons, M., Trajkovic, K., 2006. Neuron-glia communication in the control of oligodendrocyte function and myelin biogenesis. $J$ Cell Sci 119, 4381-4389.

Simpson, J.C., Griffiths, G., Wessling-Resnick, M., Fransen, J.A., Bennett, H., Jones, A.T., 2004. A role for the small GTPase Rab21 in the early endocytic pathway. J Cell Sci $117,6297-6311$.

Sinka, R., Gillingham, A.K., Kondylis, V., Munro, S., 2008. Golgi coiled-coil proteins contain multiple binding sites for Rab family G proteins. The Journal of cell biology 183, 607615.

Sklan, E.H., Serrano, R.L., Einav, S., Pfeffer, S.R., Lambright, D.G., Glenn, J.S., 2007. TBC1D20 is a Rab1 GTPase-activating protein that mediates hepatitis $\mathrm{C}$ virus replication. J Biol Chem 282, 36354-36361.

Smith, C.M., Mayer, J.A., Duncan, I.D., 2013. Autophagy promotes oligodendrocyte survival and function following dysmyelination in a long-lived myelin mutant. $J$ Neurosci 33, 8088-8100.

Smits, P., Bolton, A.D., Funari, V., Hong, M., Boyden, E.D., Lu, L., Manning, D.K., Dwyer, N.D., Moran, J.L., Prysak, M., Merriman, B., Nelson, S.F., Bonafe, L., Superti-Furga, A., Ikegawa, S., Krakow, D., Cohn, D.H., Kirchhausen, T., Warman, M.L., Beier, D.R., 2010. Lethal skeletal dysplasia in mice and humans lacking the golgin GMAP-210. The New England journal of medicine 362, 206-216.

Sohda, M., Misumi, Y., Yamamoto, A., Nakamura, N., Ogata, S., Sakisaka, S., Hirose, S., Ikehara, Y., Oda, K., 2010. Interaction of Golgin-84 with the COG complex mediates the intra-Golgi retrograde transport. Traffic 11, 1552-1566.

Sohda, M., Misumi, Y., Yoshimura, S., Nakamura, N., Fusano, T., Ogata, S., Sakisaka, S., Ikehara, Y., 2007. The interaction of two tethering factors, p115 and COG complex, is required for Golgi integrity. Traffic 8, 270-284.

Song, J.W., Misgeld, T., Kang, H., Knecht, S., Lu, J., Cao, Y., Cotman, S.L., Bishop, D.L., Lichtman, J.W., 2008. Lysosomal activity associated with developmental axon pruning. J Neurosci 28, 8993-9001.

Sotelo-Silveira, J.R., Calliari, A., Kun, A., Koenig, E., Sotelo, J.R., 2006. RNA trafficking in axons. Traffic 7, 508-515.

Stadel, D., Millarte, V., Tillmann, K.D., Huber, J., Tamin-Yecheskel, B.C., Akutsu, M., Demishtein, A., Ben-Zeev, B., Anikster, Y., Perez, F., Dotsch, V., Elazar, Z., Rogov, V., Farhan, H., Behrends, C., 2015. TECPR2 Cooperates with LC3C to Regulate COPII-Dependent ER Export. Molecular cell 60, 89-104.

Starling, G.P., Yip, Y.Y., Sanger, A., Morton, P.E., Eden, E.R., Dodding, M.P., 2016. Folliculin directs the formation of a Rab34-RILP complex to control the nutrientdependent dynamic distribution of lysosomes. EMBO reports 17, 823-841.

Starr, T., Sun, Y., Wilkins, N., Storrie, B., 2010. Rab33b and Rab6 are functionally overlapping regulators of Golgi homeostasis and trafficking. Traffic 11, 626-636.

Stiess, M., Maghelli, N., Kapitein, L.C., Gomis-Ruth, S., Wilsch-Brauninger, M., Hoogenraad, C.C., Tolic-Norrelykke, I.M., Bradke, F., 2010. Axon extension occurs independently of centrosomal microtubule nucleation. Science 327, 704-707.

Stiles, J., Jernigan, T.L., 2010. The basics of brain development. Neuropsychology review 20, 327-348.

Sun, Y., Shestakova, A., Hunt, L., Sehgal, S., Lupashin, V., Storrie, B., 2007. Rab6 regulates both ZW10/RINT-1 and conserved oligomeric Golgi complex-dependent Golgi trafficking and homeostasis. Mol Biol Cell 18, 4129-4142.

Surma, M.A., Klose, C., Simons, K., 2012. Lipid-dependent protein sorting at the trans-Golgi network. Biochim Biophys Acta 1821, 1059-1067. 
Susuki, K., Rasband, M.N., 2008. Molecular mechanisms of node of Ranvier formation. Curr Opin Cell Biol 20, 616-623.

Takahashi, S., Kubo, K., Waguri, S., Yabashi, A., Shin, H.W., Katoh, Y., Nakayama, K., 2012. Rab11 regulates exocytosis of recycling vesicles at the plasma membrane. J Cell Sci 125, 4049-4057.

Tooze, S.A., Schiavo, G., 2008. Liaisons dangereuses: autophagy, neuronal survival and neurodegeneration. Curr Opin Neurobiol 18, 504-515.

Torre, E.R., Steward, O., 1996. Protein synthesis within dendrites: glycosylation of newly synthesized proteins in dendrites of hippocampal neurons in culture. J Neurosci 16, 5967-5978.

Valsdottir, R., Hashimoto, H., Ashman, K., Koda, T., Storrie, B., Nilsson, T., 2001. Identification of rabaptin-5, rabex-5, and GM130 as putative effectors of rab33b, a regulator of retrograde traffic between the Golgi apparatus and ER. FEBS Lett 508, 201209.

Vanmarsenille, L., Giannandrea, M., Fieremans, N., Verbeeck, J., Belet, S., Raynaud, M., Vogels, A., Mannik, K., Ounap, K., Jacqueline, V., Briault, S., Van Esch, H., D'Adamo, P., Froyen, G., 2014. Increased dosage of RAB39B affects neuronal development and could explain the cognitive impairment in male patients with distal Xq28 copy number gains. Hum Mutat 35, 377-383.

Vazquez-Martinez, R., Cruz-Garcia, D., Duran-Prado, M., Peinado, J.R., Castano, J.P., Malagon, M.M., 2007. Rab18 inhibits secretory activity in neuroendocrine cells by interacting with secretory granules. Traffic 8, 867-882.

Vazquez-Martinez, R., Malagon, M.M., 2011. Rab proteins and the secretory pathway: the case of rab18 in neuroendocrine cells. Frontiers in endocrinology 2, 1.

Villarroel-Campos, D., Gastaldi, L., Conde, C., Caceres, A., Gonzalez-Billault, C., 2014. Rabmediated trafficking role in neurite formation. Journal of neurochemistry 129, 240-248.

Vinogradova, T., Paul, R., Grimaldi, A.D., Loncarek, J., Miller, P.M., Yampolsky, D., Magidson, V., Khodjakov, A., Mogilner, A., Kaverina, I., 2012. Concerted effort of centrosomal and Golgi-derived microtubules is required for proper Golgi complex assembly but not for maintenance. Mol Biol Cell 23, 820-833.

Wang, C., Liang, C.C., Bian, Z.C., Zhu, Y., Guan, J.L., 2013. FIP200 is required for maintenance and differentiation of postnatal neural stem cells. Nat Neurosci 16, 532542.

Wang, C., Yoo, Y., Fan, H., Kim, E., Guan, K.L., Guan, J.L., 2010. Regulation of Integrin beta 1 recycling to lipid rafts by Rab1a to promote cell migration. J Biol Chem 285, 2939829405.

Wang, H., Falk, M.J., Wensel, C., Traboulsi, E.I. 1993. Cohen Syndrome. In: GeneReviews(R). Eds. R.A. Pagon, M.P. Adam, H.H. Ardinger, S.E. Wallace, A. Amemiya, L.J.H. Bean, T.D. Bird, C.T. Fong, H.C. Mefford, R.J.H. Smith, K. Stephens: Seattle (WA).

Wang, L., Liang, Z., Li, G., 2011. Rab22 controls NGF signaling and neurite outgrowth in PC12 cells. Mol Biol Cell 22, 3853-3860.

Wang, S., Ma, Z., Xu, X., Wang, Z., Sun, L., Zhou, Y., Lin, X., Hong, W., Wang, T., 2014. A role of Rab29 in the integrity of the trans-Golgi network and retrograde trafficking of mannose-6-phosphate receptor. PLoS One 9, e96242.

Wanschers, B.F., van de Vorstenbosch, R., Schlager, M.A., Splinter, D., Akhmanova, A., Hoogenraad, C.C., Wieringa, B., Fransen, J.A., 2007. A role for the Rab6B BicaudalD1 interaction in retrograde transport in neuronal cells. Experimental cell research 313 , 3408-3420.

Warburg, M., Sjo, O., Fledelius, H.C., Pedersen, S.A., 1993. Autosomal recessive microcephaly, microcornea, congenital cataract, mental retardation, optic atrophy, and hypogenitalism. Micro syndrome. Am J Dis Child 147, 1309-1312. 
Wasmeier, C., Romao, M., Plowright, L., Bennett, D.C., Raposo, G., Seabra, M.C., 2006. Rab38 and Rab32 control post-Golgi trafficking of melanogenic enzymes. The Journal of cell biology 175, 271-281.

Weide, T., Bayer, M., Koster, M., Siebrasse, J.P., Peters, R., Barnekow, A., 2001. The Golgi matrix protein GM130: a specific interacting partner of the small GTPase rab1b. EMBO reports 2, 336-341.

Wen, H., Zhan, L., Chen, S., Long, L., Xu, E., 2017. Rab7 may be a novel therapeutic target for neurologic diseases as a key regulator in autophagy. J Neurosci Res.

White, J.A., 2nd, Anderson, E., Zimmerman, K., Zheng, K.H., Rouhani, R., Gunawardena, S., 2015. Huntingtin differentially regulates the axonal transport of a sub-set of Rabcontaining vesicles in vivo. Hum Mol Genet 24, 7182-7195.

White, R., Gonsior, C., Kramer-Albers, E.M., Stohr, N., Huttelmaier, S., Trotter, J., 2008. Activation of oligodendroglial Fyn kinase enhances translation of mRNAs transported in hnRNP A2-dependent RNA granules. The Journal of cell biology 181, 579-586.

White, R., Kramer-Albers, E.M., 2014. Axon-glia interaction and membrane traffic in myelin formation. Frontiers in cellular neuroscience 7, 284.

Willett, R., Ungar, D., Lupashin, V., 2013. The Golgi puppet master: COG complex at center stage of membrane trafficking interactions. Histochemistry and cell biology 140, 271283.

Wilson, G.R., Sim, J.C., McLean, C., Giannandrea, M., Galea, C.A., Riseley, J.R., Stephenson, S.E., Fitzpatrick, E., Haas, S.A., Pope, K., Hogan, K.J., Gregg, R.G., Bromhead, C.J., Wargowski, D.S., Lawrence, C.H., James, P.A., Churchyard, A., Gao, Y., Phelan, D.G., Gillies, G., Salce, N., Stanford, L., Marsh, A.P., Mignogna, M.L., Hayflick, S.J., Leventer, R.J., Delatycki, M.B., Mellick, G.D., Kalscheuer, V.M., D'Adamo, P., Bahlo, M., Amor, D.J., Lockhart, P.J., 2014. Mutations in RAB39B cause X-linked intellectual disability and early-onset Parkinson disease with alpha-synuclein pathology. Am J Hum Genet 95, 729-735.

Wilson, J.D., Shelby, S.A., Holowka, D., Baird, B., 2016. Rab11 Regulates the Mast Cell Exocytic Response. Traffic 17, 1027-1041.

Wu, Q., Sun, X., Yue, W., Lu, T., Ruan, Y., Chen, T., Zhang, D., 2016. RAB18, a protein associated with Warburg Micro syndrome, controls neuronal migration in the developing cerebral cortex. Molecular brain 9, 19.

Wu, X., Steet, R.A., Bohorov, O., Bakker, J., Newell, J., Krieger, M., Spaapen, L., Kornfeld, S., Freeze, H.H., 2004. Mutation of the COG complex subunit gene COG7 causes a lethal congenital disorder. Nat Med 10, 518-523.

Yadav, S., Linstedt, A.D., 2011. Golgi positioning. Cold Spring Harbor perspectives in biology 3.

Yadav, S., Puri, S., Linstedt, A.D., 2009. A primary role for Golgi positioning in directed secretion, cell polarity, and wound healing. Mol Biol Cell 20, 1728-1736.

Yamaguchi, H., Arakawa, S., Kanaseki, T., Miyatsuka, T., Fujitani, Y., Watada, H., Tsujimoto, Y., Shimizu, S., 2016. Golgi membrane-associated degradation pathway in yeast and mammals. EMBO J.

Yamamoto, A., Yue, Z., 2014. Autophagy and its normal and pathogenic states in the brain. Anпи Rev Neurosci 37, 55-78.

Yang, S., Rosenwald, A.G., 2016. Autophagy in Saccharomyces cerevisiae requires the monomeric GTP-binding proteins, Arll and Ypt6. Autophagy, 1-17.

Yau, K.W., Schatzle, P., Tortosa, E., Pages, S., Holtmaat, A., Kapitein, L.C., Hoogenraad, C.C., 2016. Dendrites In Vitro and In Vivo Contain Microtubules of Opposite Polarity and Axon Formation Correlates with Uniform Plus-End-Out Microtubule Orientation. $J$ Neurosci 36, 1071-1085.

Ye, B., Zhang, Y., Song, W., Younger, S.H., Jan, L.Y., Jan, Y.N., 2007. Growing dendrites and axons differ in their reliance on the secretory pathway. Cell 130, 717-729. 
Ye, B., Zhang, Y.W., Jan, L.Y., Jan, Y.N., 2006. The secretory pathway and neuron polarization. J Neurosci 26, 10631-10632.

Yla-Anttila, P., Mikkonen, E., Happonen, K.E., Holland, P., Ueno, T., Simonsen, A., Eskelinen, E.L., 2015. RAB24 facilitates clearance of autophagic compartments during basal conditions. Autophagy 11, 1833-1848.

Yoo, S., van Niekerk, E.A., Merianda, T.T., Twiss, J.L., 2010. Dynamics of axonal mRNA transport and implications for peripheral nerve regeneration. Exp Neurol 223, 19-27.

Young, A.R., Chan, E.Y., Hu, X.W., Kochl, R., Crawshaw, S.G., High, S., Hailey, D.W., Lippincott-Schwartz, J., Tooze, S.A., 2006. Starvation and ULK1-dependent cycling of mammalian Atg9 between the TGN and endosomes. J Cell Sci 119, 3888-3900.

Young, J., Menetrey, J., Goud, B., 2010. RAB6C is a retrogene that encodes a centrosomal protein involved in cell cycle progression. Journal of molecular biology 397, 69-88.

Zheng, J.Y., Koda, T., Arimura, Y., Kishi, M., Kakinuma, M., 1997. Structure and expression of the mouse S10 gene. Biochim Biophys Acta 1351, 47-50.

Zheng, J.Y., Koda, T., Fujiwara, T., Kishi, M., Ikehara, Y., Kakinuma, M., 1998. A novel Rab GTPase, Rab33B, is ubiquitously expressed and localized to the medial Golgi cisternae. J Cell Sci 111 ( Pt 8), 1061-1069.

Zhou, C., Ma, K., Gao, R., Mu, C., Chen, L., Liu, Q., Luo, Q., Feng, D., Zhu, Y., Chen, Q., 2017. Regulation of mATG9 trafficking by Src- and ULK1-mediated phosphorylation in basal and starvation-induced autophagy. Cell research 27, 184-201.

Zhou, W., Chang, J., Wang, X., Savelieff, M.G., Zhao, Y., Ke, S., Ye, B., 2014. GM130 is required for compartmental organization of dendritic golgi outposts. Curr Biol 24, 1227-1233.

Zhu, X., Kaverina, I., 2013. Golgi as an MTOC: making microtubules for its own good. Histochemistry and cell biology 140, 361-367.

Zmuda, J.F., Rivas, R.J., 1998. The Golgi apparatus and the centrosome are localized to the sites of newly emerging axons in cerebellar granule neurons in vitro. Cell motility and the cytoskeleton $41,18-38$.

Zong, M., Satoh, A., Yu, M.K., Siu, K.Y., Ng, W.Y., Chan, H.C., Tanner, J.A., Yu, S., 2012. TRAPPC9 mediates the interaction between 150 and COPII vesicles at the target membrane. PLoS One 7, e29995.

Zoppino, F.C., Militello, R.D., Slavin, I., Alvarez, C., Colombo, M.I., 2010. Autophagosome formation depends on the small GTPase Rab1 and functional ER exit sites. Traffic 11, 1246-1261.

Zou, W., Yadav, S., DeVault, L., Nung Jan, Y., Sherwood, D.R., 2015. RAB-10-Dependent Membrane Transport Is Required for Dendrite Arborization. PLoS Genet 11, e1005484.

Zuk, P.A., Elferink, L.A., 2000. Rab15 differentially regulates early endocytic trafficking. $J$ Biol Chem 275, 26754-26764. 


\section{Legends to Figures}

\section{Figure 1.}

Golgi-associated postnatal microcephaly-causing factors and their link with RAB proteins in anterograde and retrograde neuronal trafficking

A. Schematic representation of the somatic Golgi apparatus, dendritic Golgi outposts and differential organization of microtubules in axons and dendrites. B. Subcellular localization of the proteins whose encoding genes have been associated with postnatal-onset microcephaly, and their known link with Golgi-associated RAB GTPases.

$\mathrm{EE}=$ Early Endosome. $\mathrm{ER}=$ Endoplasmic Reticulum. ERGIC $=$ Endoplasmic Reticulum-Golgi Intermediate Compartment. GA = Golgi Apparatus. GO = Golgi Outposts. GS = Golgi Satellites. $\mathrm{L} / \mathrm{A}=$ Lysosome/Autophagosome. $\mathrm{LE}=$ Late Endosome. $\mathrm{MT}=$ MicroTubules. $\mathrm{Nu}=$ Nucleus. RE $=$ Recycling Endosome. TGN $=$ Trans Golgi Network.

\section{Figure 2.}

Time-course of the main neurodevelopmental steps in human and correspondence with the Occipito-Frontal Circumference progression

Schematic representation of the main neurodevelopmental mechanisms contributing to brain growth illustrating that gliogenesis, synaptogenesis, myelination and synaptic pruning mainly occur during childhood (although initiated before birth) and significantly contribute to postnatal brain growth (black curve). The red and blue curves illustrate the progression of occipitofrontal circumference (OFC) in patients affected with postnatal microcephaly (POM) and primary microcephaly $(\mathrm{PM})$ respectively. 
TABLE I. GA/TGN-associated RAB GTPases and their associated function(s).

\begin{tabular}{|c|c|c|c|}
\hline $\begin{array}{l}\text { RAB GTPase } \\
\text { Sub-family }\end{array}$ & Subcellular location & Known intracellular function & References \\
\hline RAB1 & $\begin{array}{l}\text { Cis-Golgi - ER/Intermediate } \\
\text { compartment }\end{array}$ & $\begin{array}{l}\text { ER-Golgi trafficking, Cell signaling, } \\
\text { Autophagy }\end{array}$ & $\begin{array}{l}\text { (Ao et al., 2014; Yang and } \\
\text { Rosenwald, 2016) }\end{array}$ \\
\hline RAB2 & $\begin{array}{l}\text { Cis-Golgi, Intermediate } \\
\text { compartment, vesicles }\end{array}$ & $\begin{array}{l}\text { Regulation of GA morphology, } \\
\text { Axonal transport }\end{array}$ & $\begin{array}{l}\text { (Aizawa and Fukuda, 2015; } \\
\text { White et al., 2015) }\end{array}$ \\
\hline RAB3 & Golgi, TGN, secretory vesicles & Exocytosis & $\begin{array}{l}\text { (Kogel et al., 2013; } \\
\text { Nishimura et al., 2008) }\end{array}$ \\
\hline RAB6 & Golgi, TGN, peroxisomes & $\begin{array}{l}\text { Golgi vesicle biogenesis, Anterograde } \\
\text { \& retrograde vesicle transport from } \\
\text { the trans-Golgi/TGN to the plasma } \\
\text { membrane or ER }\end{array}$ & $\begin{array}{l}\text { (Heffernan and Simpson, } \\
\text { 2014; Majeed et al., } \\
\text { 2014) }\end{array}$ \\
\hline RAB7 & TGN, late endosomes & $\begin{array}{l}\text { Transport to late endocytic } \\
\text { compartments, Cell signaling, } \\
\text { Autophagy }\end{array}$ & $\begin{array}{l}\text { (Ao et al., 2014; Guerra and } \\
\text { Bucci, 2016) }\end{array}$ \\
\hline RAB8 & TGN, vesicles, tubular structures & $\begin{array}{l}\text { Membrane trafficking from the TGN, } \\
\text { Exocytosis, Membrane recycling, } \\
\text { Autophagy }\end{array}$ & $\begin{array}{l}\text { (Ao et al., 2014; Peranen, } \\
\text { 2011) }\end{array}$ \\
\hline RAB9 & Golgi, TGN, late endosomes & $\begin{array}{l}\text { Endosome-to-TGN transport, } \\
\text { Transport within the endolysosomal } \\
\text { system, Golgi targeting of } \\
\text { glycosphingolipids, } \\
\text { Autophagy }\end{array}$ & $\begin{array}{l}\text { (Ao et al., 2014; Kucera et } \\
\text { al., 2016) }\end{array}$ \\
\hline RAB10 & $\begin{array}{l}\text { Golgi, ER tubular intermediates, } \\
\text { peroxisomes }\end{array}$ & $\begin{array}{l}\text { Membrane trafficking from the } \\
\text { Golgi/ER, the TGN and recycling } \\
\text { endosomes, Dendritic transport }\end{array}$ & $\begin{array}{l}\text { (Homma and Fukuda, 2016; } \\
\text { Zou et al., 2015) }\end{array}$ \\
\hline RAB11 & $\begin{array}{l}\text { Golgi, ER tubular intermediates, TGN, } \\
\text { recycling endosomes }\end{array}$ & $\begin{array}{l}\text { Recycling endosomes, Exocytosis, } \\
\text { Autophagy }\end{array}$ & $\begin{array}{l}\text { (Ao et al., 2014; Takahashi } \\
\text { et al., 2012; Wilson et al., } \\
\text { 2016) }\end{array}$ \\
\hline RAB12 & $\begin{array}{l}\text { Golgi, early endosomes, toxin- } \\
\text { induced membrane invaginations }\end{array}$ & $\begin{array}{l}\text { Transport within the endolysosomal } \\
\text { system, Retrograde transport to TGN, } \\
\text { Autophagy }\end{array}$ & $\begin{array}{l}\text { (Matsui and Fukuda, 2011, } \\
\text { 2013; Rydell et al., 2014) }\end{array}$ \\
\hline RAB13 & TGN, endosomes, plasma membrane & $\begin{array}{l}\text { Recycling endosomes, Membrane } \\
\text { trafficking from the TGN }\end{array}$ & $\begin{array}{l}\text { (Kobayashi et al., 2014; } \\
\text { Nokes et al., 2008) }\end{array}$ \\
\hline RAB14 & $\begin{array}{l}\text { Golgi, TGN, early endosomes, } \\
\text { peroxisomes }\end{array}$ & $\begin{array}{l}\text { membrane trafficking between the } \\
\text { Golgi complex and endosomes, } \\
\text { Autophagy }\end{array}$ & $\begin{array}{l}\text { (Junutula et al., 2004; Okai } \\
\text { et al., 2015) }\end{array}$ \\
\hline RAB15 & TGN, early and recycling endosomes & Early endocytic trafficking & (Zuk and Elferink, 2000) \\
\hline RAB18 & $\begin{array}{l}\text { Cis-Golgi - ER, endosomes, } \\
\text { peroxisomes, secretory granules, lipid } \\
\text { droplets }\end{array}$ & $\begin{array}{l}\text { ER structure, ER-Golgi trafficking, } \\
\text { secretory granule transport }\end{array}$ & $\begin{array}{l}\text { (Dejgaard et al., 2008; } \\
\text { Gerondopoulos et al., } \\
\text { 2014; Vazquez-Martinez } \\
\text { and Malagon, 2011) }\end{array}$ \\
\hline RAB19 & Golgi, vesicles & Axonal transport & $\begin{array}{l}\text { (Sinka et al., 2008; White et } \\
\text { al., 2015) }\end{array}$ \\
\hline RAB21 & TGN, endosomes & $\begin{array}{l}\text { Neurite Outgrowth } \\
\text { Early endocytic pathway, } \\
\text { Autophagy }\end{array}$ & $\begin{array}{l}\text { (Burgo et al., 2009; Jean et } \\
\text { al., 2015; Simpson et al., } \\
\text { 2004) }\end{array}$ \\
\hline RAB22 & Trans-Golgi, TGN, endosomes & $\begin{array}{l}\text { Neurite Outgrowth } \\
\text { Early endocytic pathway }\end{array}$ & $\begin{array}{l}\text { (Dutta and Donaldson, } \\
\text { 2015; Rodriguez-Gabin et } \\
\text { al., 2001; Wang et al., } \\
\text { 2011) }\end{array}$ \\
\hline
\end{tabular}




\begin{tabular}{|c|c|c|c|}
\hline RAB24 & $\begin{array}{l}\text { ER, Cis-Golgi, late endosomes, } \\
\text { Autophagosomes, midbody }\end{array}$ & $\begin{array}{l}\text { endosome-lysosome degradative } \\
\text { pathway, Cytokinesis, } \\
\text { Autophagy }\end{array}$ & $\begin{array}{l}\text { (Amaya et al., 2016; } \\
\text { Militello et al., 2013; } \\
\text { Olkkonen et al., 1993; } \\
\text { Yla-Anttila et al., 2015) }\end{array}$ \\
\hline RAB26 & Golgi, synaptic vesicles, Lysosomes & $\begin{array}{l}\text { Golgi-to-cell surface traffic, lysosome } \\
\text { traffic, } \\
\text { Autophagy }\end{array}$ & $\begin{array}{l}\text { (Binotti et al., 2015; Jin and } \\
\text { Mills, 2014; Li et al., } \\
\text { 2012) }\end{array}$ \\
\hline RAB27 & TGN, secretory granules & $\begin{array}{l}\text { secretory granule transport and } \\
\text { exocytosis }\end{array}$ & (Fukuda, 2013) \\
\hline RAB29 & Golgi, TGN, recycling endosomes & $\begin{array}{l}\text { Integrity of the TGN, Recycling from } \\
\text { late endosomes to the TGN }\end{array}$ & $\begin{array}{l}\text { (Onnis et al., 2015; Wang et } \\
\text { al., 2014) }\end{array}$ \\
\hline RAB30 & Golgi & $\begin{array}{l}\text { Integrity of the Golgi apparatus, } \\
\text { Autophagy }\end{array}$ & $\begin{array}{l}\text { (Kelly et al., 2012; Oda et } \\
\text { al., 2016) }\end{array}$ \\
\hline RAB33 & Golgi, synaptic vesicles & $\begin{array}{l}\text { axonal transport (RAB33A), } \\
\text { Retrograde Golgi-to-ER transport } \\
\text { (RAB33B), Autophagy }\end{array}$ & $\begin{array}{l}\text { (Ao et al., 2014; Itoh et al., } \\
\text { 2008) }\end{array}$ \\
\hline RAB34 & Golgi, Lysosomes & $\begin{array}{l}\text { Intra-Golgi anterograde transport, } \\
\text { lysosomes trafficking, } \\
\text { Autophagy }\end{array}$ & $\begin{array}{l}\text { (Goldenberg et al., 2007; } \\
\text { Kasmapour et al., 2012; } \\
\text { Starling et al., 2016) }\end{array}$ \\
\hline RAB35 & TGN, endosomes, plasma membrane & $\begin{array}{l}\text { Endocytic recycling, Neurite } \\
\text { Outgrowth, Exosome release, } \\
\text { Cytokinesis \& cell polarity }\end{array}$ & (Klinkert and Echard, 2016) \\
\hline RAB36 & $\begin{array}{l}\text { Golgi, Lysosomes, recycling } \\
\text { endosomes }\end{array}$ & $\begin{array}{l}\text { Endosomes and lysosomes } \\
\text { trafficking, Neurite Outgrowth }\end{array}$ & $\begin{array}{l}\text { (Chen et al., 2010; } \\
\text { Kobayashi et al., 2014) }\end{array}$ \\
\hline RAB38 & ER, Golgi, TGN, post-Golgi vesicles & $\begin{array}{l}\text { biogenesis of } \\
\text { lysosomes/melanosomes }\end{array}$ & $\begin{array}{l}\text { (Bultema and Di Pietro, } \\
\text { 2013; Osanai et al., 2005; } \\
\text { Wasmeier et al., 2006) }\end{array}$ \\
\hline RAB39 & Golgi & $\begin{array}{l}\text { Neurite morphology, } \\
\text { Autophagy }\end{array}$ & $\begin{array}{l}\text { (Chen et al., 2003; Corbier } \\
\text { and Sellier, 2016; Mori et } \\
\text { al., 2013; Seto et al., } \\
\text { 2013) }\end{array}$ \\
\hline RAB40 & $\begin{array}{l}\text { Golgi, plasma membrane, recycling } \\
\text { endosomes }\end{array}$ & $\begin{array}{l}\text { Vesicle transport in } \\
\text { oligodendrocytes, cell signaling }\end{array}$ & $\begin{array}{l}\text { (Lee et al., 2007; Rodriguez- } \\
\text { Gabin et al., 2004) }\end{array}$ \\
\hline RAB41 & Golgi & $\begin{array}{l}\text { Golgi apparatus organization, ER- } \\
\text { Golgi trafficking }\end{array}$ & (Liu et al., 2013) \\
\hline RAB43 & Golgi & $\begin{array}{l}\text { Integrity of the Golgi apparatus, } \\
\text { anterograde trafficking of cargo } \\
\text { through the medial Golgi, Retrograde } \\
\text { transport from endosomes to Golgi }\end{array}$ & $\begin{array}{l}\text { (Cox et al., 2016; Dejgaard } \\
\text { et al., 2008) }\end{array}$ \\
\hline
\end{tabular}

ER=Endoplasmic Reticulum. GA=Golgi apparatus. TGN=Trans Golgi Network. 
TABLE II. Genetic disorders associated with POM and Golgi-associated factors.

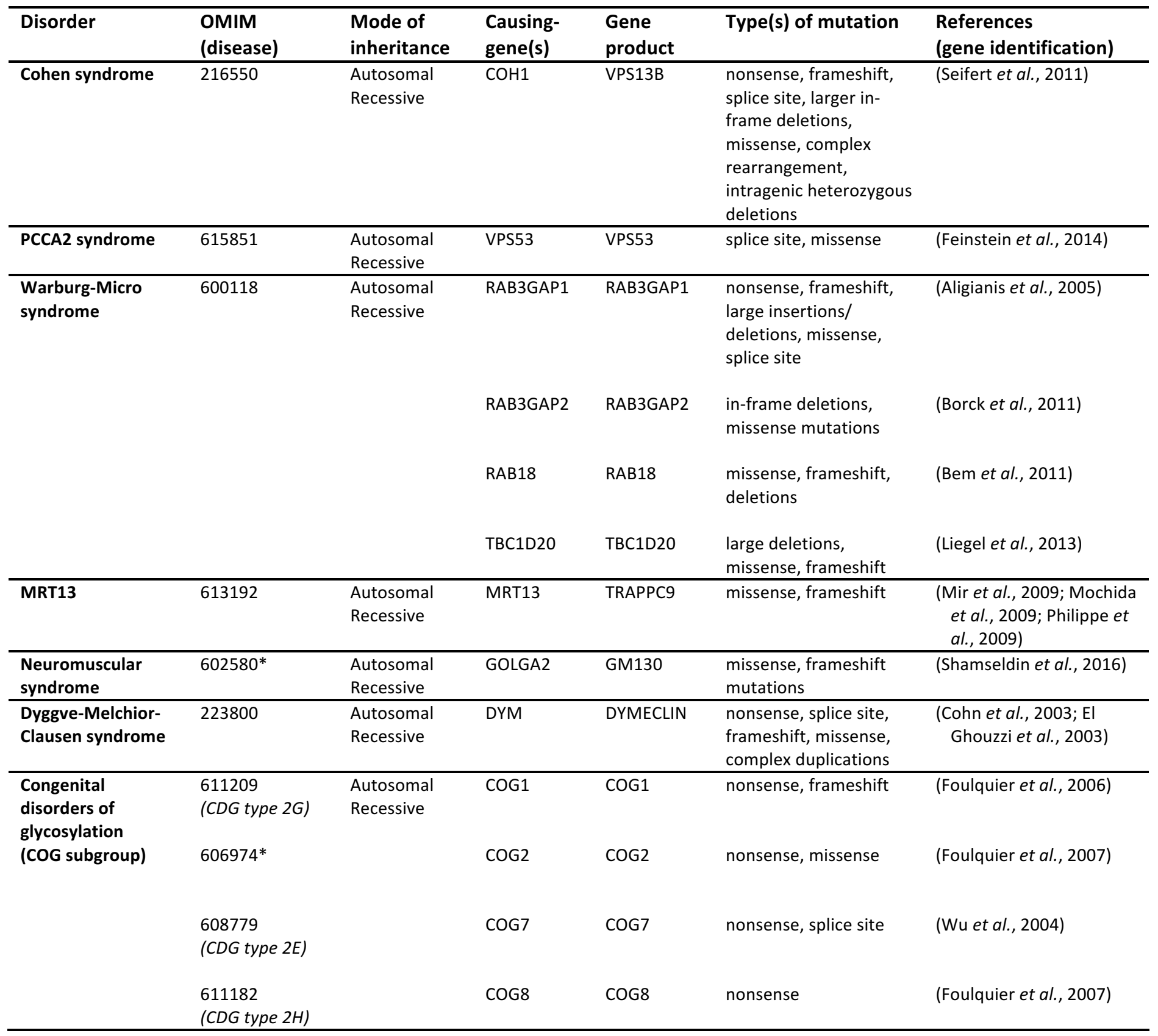

* OMIM reference corresponds to the gene instead of the disease 